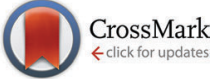

Cite this: Phys. Chem. Chem. Phys., 2015, 17, 16494

Received 30th March 2015, Accepted 29th May 2015

DOI: $10.1039 / c 5 c p 01841 b$

www.rsc.org/pccp

\title{
Stability and ionic mobility in argyrodite-related lithium-ion solid electrolytes $\dagger$
}

\begin{abstract}
Hao Min Chen, Chen Maohua and Stefan Adams*
In the search for fast lithium-ion conducting solids for the development of safe rechargeable all-solidstate batteries with high energy density, thiophosphates and related compounds have been demonstrated to be particularly promising both because of their record ionic conductivities and their typically low charge transfer resistances. In this work we explore a wide range of known and predicted thiophosphates with a particular focus on the cubic argyrodite phase with a robust three-dimensional network of ion migration pathways. Structural and hydrolysis stability are calculated employing density functional method in combination with a generally applicable method of predicting the relevant critical reaction. The activation energy for ion migration in these argyrodites is then calculated using the empirical bond valence pathway method developed in our group, while bandgaps of selected argyrodites are calculated as a basis for assessing the electrochemical window. Findings for the lithium compounds are also compared to those of previously known copper argyrodites and hypothetical sodium argyrodites. Therefrom, guidelines for experimental work are derived to yield phases with the optimum balance between chemical stability and ionic conductivity in the search for practical lithium and sodium solid electrolyte materials.
\end{abstract}

\section{Introduction}

Developing electrochemical storage devices with high energy densities is vitally important for powering our future society and the increasing demand for high energy and high-power rechargeable batteries has become the major driving force for further advances in battery technology. The available organic liquid electrolytes more and more are recognised as a bottleneck in the effort to develop safe high-performance systems. Instead, inorganic fast ion-conducting solids ${ }^{1,2}$ with high electrochemical stability in contact with the anode (often Li metal) and cathode material, favourable mechanical properties, cost-efficient low temperature synthesis and sufficient kinetic stability for operation over a wide temperature window increasingly appear as key components in most of the promising next generation energy storage systems including both all-solid state batteries as well as (Li-air, Li-sulphur, Li-redox flow) battery concepts wherein electrode liquids or slurries are combined with solid electrolytes to facilitate scalability.

High ionic conductivity is essential to achieve a high capacity, while low electronic conductivity mitigates the electron transport through the solid electrolyte, thus preventing self-discharge of

Department of Materials Science and Engineering, National University of Singapore, Singapore 117575, Singapore.E-mail: mseasn@nus.edu.sg

$\dagger$ Electronic supplementary information (ESI) available: Program to evaluate critical reactions; tabulated values used to plot graphs. See DOI: 10.1039/ c5cp01841b the batteries. On the other hand a certain local concentration of mobile electrons at the electrode:electrolyte interfaces mitigates charge transfer resistances (which may become a challenge for some oxide solid electrolytes). Among the solid-state Li ion conductors developed so far, the most favourable characteristics for application in electrochemical cells in terms of record ionic conductivity and lowest charge transfer resistances have been achieved by lithium thiophosphates and related compounds such as $\mathrm{Li}_{7} \mathrm{P}_{3} \mathrm{~S}_{11},{ }^{3,4}$ LGPS, ${ }^{5,6}$ thio-Lisicon ${ }^{7}$ and a recent report on a " $\mathrm{Li}_{7} \mathrm{P}_{2} \mathrm{~S}_{8} \mathrm{I}$ " of unknown structure. ${ }^{8}$ Therefore, it is critical to explore more in detail sulphide-based solid electrolytes to identify the most favourable compositions and structures for application as solid electrolytes in batteries. One of the ways to widen the range of known solid electrolytes with technologically interesting performance is to explore compounds containing more than one type of anions. Solid solutions of oxide- or sulphide-based solid electrolytes with alkali halides have in the past proven to be a successful strategy to enhance ionic conductivity in a wide range of $\mathrm{Ag}^{+}, \mathrm{Cu}^{+}$or alkali based systems. ${ }^{2,9}$ This straightforwardly leads to the exploration of the fast-ion conducting halide-containing lithium argyrodites that are in the focus of this work. ${ }^{10}$

The argyrodite family of compounds with the general formula $\mathrm{A}_{12-m-x}{ }^{+}\left(\mathrm{M}^{m+} \mathrm{Y}_{4}{ }^{2-}\right) \mathrm{Y}_{2-x}{ }^{2-} \mathrm{X}_{x}{ }^{-}$where $\mathrm{A}^{+}=\mathrm{Li}^{+}, \mathrm{Cu}^{+}, \mathrm{Ag}^{+} ; \mathrm{M}^{m+}=$ $\mathrm{Si}^{4+}, \mathrm{Ge}^{4+}, \mathrm{Sn}^{4+}, \mathrm{P}^{5+}, \mathrm{As}^{5+} ; \mathrm{Y}^{2-}=\mathrm{O}^{2-}, \mathrm{S}^{2-}, \mathrm{Se}^{2-}, \mathrm{Te}^{2-} ; \mathrm{X}^{-}=\mathrm{Cl}^{-}$, $\mathrm{Br}^{-}, \mathrm{I}^{-} ; 0 \leq x \leq 2$ are named after the mineral $\mathrm{Ag}_{8} \mathrm{GeS}_{6} \cdot{ }^{11}$ Only a few argyrodites with trivalent $\mathrm{M}^{3+}=\mathrm{Fe}^{3+}, \mathrm{Al}^{3+}, \mathrm{Ga}^{3+}$ have been reported. ${ }^{12} \mathrm{~A}$ wider range of silver and copper argyrodites had 
been described 70 years ago ${ }^{13}$ and subsequently studied more in depth by Kuhs et al. ${ }^{14}$ and Evain et al. ${ }^{15}$ Temperature-dependent order-disorder transitions and cationic disorder in the hightemperature phase yield moderately high ionic conductivity for the high-temperature polymorphs of quaternary $\mathrm{Cu}$ and Ag-containing argyrodites ${ }^{14,16}$ while the corresponding halidefree ternary argyrodites are generally found to be semiconductors, for which changes in the fundamental absorption-edge related to the polymorphic transitions were evidenced. ${ }^{17}$ Lithium argyrodites first reported by the Deiseroth group ${ }^{10}$ are promising candidates for solid electrolytes. The most commonly studied argyrodite-type lithium ion conductor, $\mathrm{Li}_{6} \mathrm{PS}_{5} \mathrm{Br}$, is reported to have a conductivity of $0.7-1 \times 10^{-3} \mathrm{~S} \mathrm{~cm}^{-1} \cdot$. $^{18,19}$ The wide electrochemical window and applicability of lithium argyrodites in various types of rechargeable all-solid batteries have been demonstrated earlier by our group. ${ }^{20,21}$ Still, as for most fast-ion conducting lithium thiophosphates, such as $\mathrm{Li}_{7} \mathrm{P}_{3} \mathrm{~S}_{11}{ }^{3}$ or LGPS, ${ }^{5,6}$ the structures of the known lithium argyrodites such as $\mathrm{Li}_{6} \mathrm{PS}_{5} \mathrm{Br}$ are only metastable limiting choices in their synthesis and raising questions about the long-term structural stability. More importantly, the lithium thiophosphates are typically unstable with respect to hydrolysis, so that they can only be handled in dry atmospheres, which is a serious cost factor for their technical application. Therefore this study aims at exploring the effect of possible changes in composition on the structural stability and hydrolysis stability.

Most argyrodites adopt a cation-disordered high-temperature cubic "aristotype" phase in space group $F \overline{4} 3 m$ (see Fig. 1a) with a characteristic anion arrangement in interpenetrating icosahedral cages, but argyrodites may also crystallize in an intermediate state of disorder in the lower-symmetry cubic space group $P 2_{1} 3$, as well as in cation-ordered low-temperature phases in orthorhombic space group $P m n 2_{1}$ (e.g. for $\mathrm{Cu}_{8} \mathrm{GeS}_{6}$ below $330 \mathrm{~K}^{22}$ ), $\operatorname{Pna}_{1}$ (e.g. for $\mathrm{Ag}_{8} \mathrm{SiS}_{6}$ below $507 \mathrm{~K}^{14}$ ) and/or a monoclinic structure in space group $C c$ (e.g. for $\left.\mathrm{Cu}_{6} \mathrm{PS}_{5} \mathrm{Br}^{23}\right)$.

For the halide-rich range of the possible argyrodite stoichiometries the argyrodite structure type is in competition to a distinct orthorhombic structure in space group Pnma (see Fig. 1b): $\mathrm{Ag}_{6}\left(\mathrm{GeS}_{4}\right) \mathrm{X}_{2}(\mathrm{X}=\mathrm{Cl}, \mathrm{Br})^{24,25}$ as well as $\mathrm{Ag}_{6}\left(\mathrm{SnS}_{4}\right) \mathrm{Br}_{2}{ }^{26}$ have been found experimentally as the first members of this family of "non-metallic filled $\mathrm{NaHg}_{2}$ phases", i.e. the partial structure of the non-metal atoms $\mathrm{S}$ and $\mathrm{X}(\mathrm{Cl}, \mathrm{Br})$ corresponds to the arrangement of $\mathrm{Na}$ and $\mathrm{Hg}$ atoms in $\mathrm{NaHg}_{2}\left(=\mathrm{X}_{2} \mathrm{~S}_{4}\right)$ with Ge located in tetrahedral holes exclusively and $\mathrm{Ag}$ located in tetrahedral as well as octahedral holes.

Besides the required high ionic and low electronic structural conductivity, a solid electrolyte also needs to exhibit high hydrolysis stability. Structural stability affects how easily a material can be synthesized and how stable it is against degradation during cycling. Hydrolysis stability is especially important for alkali sulphide materials, most of which will rapidly degrade in contact with humid air (or aqueous catholytes). Therefore, a dry atmosphere is critically required throughout their preparation and battery assembly, increasing production costs and decreasing reliability of the batteries. When comparing compounds containing the same type of elements and hence

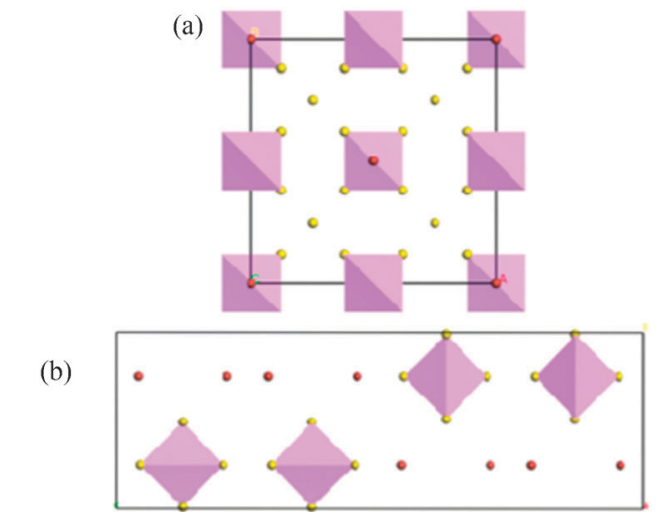

Fig. 1 (a) Argyrodite structure and (b) $\mathrm{NaHg}_{2}$-related structure. Purple tetrahedrons represent $\mathrm{MS}_{4}{ }^{8-m}$ groups; red spheres represent $\mathrm{X}^{-}$anions; the mobile $\mathrm{A}^{+}$ions are omitted.

the same potential decomposition products, the hydrolysis stability is obviously related to the structural stability of the compound.

While structural stability, hydrolysis stability, ionic conductivity and electronic conductivity can in principle be determined experimentally, synthesis of some materials could be difficult, expensive or hazardous, so that computational approaches become beneficial to estimate these properties of materials, thus providing guidance to experimentalists whether synthesizing a new material appears worthwhile. Structural stability and hydrolysis stability can be assessed from the dissociation energy of the material. While the structural stabilities of various phases in the quaternary system $\mathrm{Li}-\mathrm{P}-\mathrm{S}-\mathrm{O}$ are available in the literature, ${ }^{27}$ in this work we designed a systematic way to examine structural and hydrolysis stability of any phase of known stoichiometry based on the calculated formation energies. Predicting the ionic conductivity requires identifying the ion migration pathways of the mobile ions and their activation energies. We employed the empirical bond valence-based softBV method developed in our group. ${ }^{28-30}$ Electronic conductivity can be estimated from the determination of the bandgap by DFT calculations.

In this work, argyrodite-type and orthorhombic $\mathrm{NaHg}_{2}$ related phases of $\mathrm{A}_{12-m-x}+\left(\mathrm{M}^{m+} \mathrm{Y}_{4}{ }^{2-}\right) \mathrm{Y}_{2-x}{ }^{2-} \mathrm{X}_{x}^{-}$with $\mathrm{A}^{+}=\mathrm{Li}^{+}$, $\mathrm{Cu}^{+}, \mathrm{Ag}^{+} ; \mathrm{M}^{m+}=\mathrm{Si}^{4+}, \mathrm{Ge}^{4+}, \mathrm{Sn}^{4+}, \mathrm{P}^{5+}, \mathrm{As}^{5+} ; \mathrm{Y}^{2-}=\mathrm{O}^{2-}, \mathrm{S}^{2-}, \mathrm{Se}^{2-}$, $\mathrm{Te}^{2-} ; \mathrm{X}^{-}=\mathrm{Cl}^{-}, \mathrm{Br}^{-}, \mathrm{I}^{-}$are studied computationally to explore the suitability of this class of materials for practical applications in energy storage systems. Their structural stability and hydrolysis stability are determined by calculating the dissociation energies of the respective relevant critical reactions from $a b$ initio data, and their ionic conductivities are assessed by empirical bond valence methods.

Depending on the halide content $x$ (that may also adopt noninteger values), the cubic argyrodite phase may exhibit various degrees of site-inversion between anions $\mathrm{X}^{-}$and $\mathrm{Y}^{2-} \cdot{ }^{10,18,19,21}$ Moreover, the effect of anion site-inversion on stability and conductivity on the argyrodites and related phases is examined in this study. To limit the computational effort, generally only stoichiometric compositions with integer values of $x=0,1,2$ are considered. 


\section{Computational methodology}

\section{Structural stability}

Structural stabilities are evaluated by the dissociation energy of the compound, which is the reaction energy of its critical reaction. Taking $\mathrm{Li}_{3} \mathrm{PS}_{4}$ for instance, its critical reaction is:

$$
\mathrm{Li}_{3} \mathrm{PS}_{4} \leftrightarrow \frac{1}{2} \mathrm{~S}+\frac{1}{2} \mathrm{Li}_{2} \mathrm{~S}+\frac{1}{2} \mathrm{Li}_{4} \mathrm{P}_{2} \mathrm{~S}_{6}
$$

Accordingly, the reaction energy is computed as:

$\Delta E=0.5 \times E\left(\mathrm{Li}_{4} \mathrm{P}_{2} \mathrm{~S}_{6}\right)+0.5 \times E\left(\mathrm{Li}_{2} \mathrm{~S}\right)+0.5 \times E(\mathrm{~S})-E\left(\mathrm{Li}_{3} \mathrm{PS}_{4}\right)$

Here, $E$ is the formation energy of the compound calculated by DFT methods. In this example, the resulting value $\Delta E=0.205 \mathrm{eV}$ is positive, suggesting that $\mathrm{Li}_{3} \mathrm{PS}_{4}$ is a stable compound and will not decompose.

\section{Formation energy of compounds}

The formation energy of a compound from its constituting elements is calculated by DFT methods as implemented in the VASP package ${ }^{31}$ based on a planewave basis set with using the Perdew-Burke-Ernzerhof (PBE) exchange-correlation parametrized general gradient approximation (GGA) ${ }^{32}$ and projector augmentedwave pseudopotentials (PAW). ${ }^{33,34}$ The cutoff threshold is set to $400 \mathrm{eV}$ and convergence is by force $<0.03 \mathrm{eV}^{-1}$. Each compound has a $k$-mesh with a density of at least $30 k$-points $\times \AA^{3}$. Although $+U$ techniques help in more precisely evaluating energies of many transition metal oxides ${ }^{35}$ such as copper oxide, it is not applied here for two reasons: $U$ values for most sulphides are not available in the literature; $U$ values for oxides and sulphides are different, but in calculating hydrolysis stability, a single consistent $U$ value would have to be used.

\section{Critical reaction}

With the formation energy of a compound known, the respective critical reaction remains to be determined in order to calculate the dissociation energy. The critical reaction is the reaction with the most negative reaction energy among all conceivable dissociation reactions of the compound. While experimental observation and experience is helpful in identifying such critical reactions, it appears to be more consistent for the screening approach of this work here to follow a generally applicable and exhaustive approach.

Consider a compound with formula $\mathrm{A}_{1 b_{1}} \mathrm{~A}_{1 b_{2}} \ldots \mathrm{A}_{m b_{m}}$, where $\mathrm{A}_{i}$ are distinct elements, $b_{i}$ are the stoichiometric ratios, and $i=1,2, \ldots, m$. Suppose there are $n$ compounds in the phase diagram of $\mathrm{A}_{1}-\mathrm{A}_{2}-\ldots-\mathrm{A}_{m}$, each is denoted by $\mathrm{A}_{1 a_{1 j}} \mathrm{~A}_{2 a_{2 j}} \ldots \mathrm{A}_{m a_{m j}}$, where $j=1,2, \ldots, n$, and $a_{i j} \geq 0$. Then all possible reaction equations can be summarized in the following form:

$$
\mathrm{A}_{1 b_{1}} \mathrm{~A}_{2 b_{2}} \ldots \mathrm{A}_{m b_{m}} \leftrightarrow x_{1} \mathbf{A}_{1 a_{11}} \mathrm{~A}_{2 a_{21}} \ldots \mathrm{A}_{m a_{m 1}}+\ldots+x_{n} \mathrm{~A}_{1 a_{1 n}} \mathrm{~A}_{2 a_{2 n}} \ldots \mathrm{A}_{m a_{m n}}
$$

with $i=1,2, \ldots, m$, where $m$ is the total number of elements, $m \geq 1$ and $j=1,2, \ldots, n$, where $n$ is the total number of compounds, $n \geq m$.
Provided that the complete list of compounds in the phase diagram is known, the search for the critical reaction can be converted into a standard linear programming problem:

Minimize $E=\mathbf{E} \cdot \mathbf{x}=E_{1} \times x_{1}+E_{2} \times x_{2}+\ldots+E_{n} \times x_{n}$, subject to the constraint $\mathbf{A} \cdot \mathbf{x}=\mathbf{b}$ where:

$\mathbf{A}=\left\{a_{i j}\right\}$ are stoichiometric numbers of each element $\mathrm{A}_{i}$ in each of the conceivable decomposition products $j$;

$\mathbf{b}=\left\{b_{i}\right\}$ are stoichiometric numbers of each element in the reference compound;

$\mathbf{E}=\left\{E_{i}\right\}$ are calculated formation energies of each compound;

$\mathbf{x}=\left\{x_{i}\right\}$ are the coefficients of each compound to which the reference compound dissociates, $\mathbf{x}$ is the unknown to be solved and $\mathbf{x} \geq 0$;

This minimization task has a unique solution and is here solved by a simple program written with GLPK libraries ${ }^{36}$ that is available from the supplementary material.

\section{Effects of anion site-inversion}

In the aristotype argyrodite structures of $\operatorname{Li}_{11-m}\left(\mathrm{M}^{m+} \mathrm{Y}_{4}\right) \mathrm{YX}$, each unit cell contains four free $\mathrm{Y}^{2-}$ anions that are not part of rigid $\left(\mathrm{MY}_{4}\right)^{(8-m)-}$ groups and four $\mathrm{X}^{-}$anions. To study the effect of anion site-inversion, the stabilities of five configurations are calculated for each composition by swapping zero to four pairs of $\mathrm{Y}^{2-} / \mathrm{X}^{-}$anions. The degree of site-inversion is defined to be $0 \%$ when all four free $\mathrm{Y}^{2-}$ anions are located at the regular $\mathrm{Y}$ site, i.e. the $4 \mathrm{~d}$ site $\ddagger\left(\frac{3}{4}, \frac{3}{4}, \frac{3}{4}\right),\left(\frac{1}{4}, \frac{1}{4}, \frac{3}{4}\right),\left(\frac{3}{4}, \frac{1}{4}, \frac{1}{4}\right),\left(\frac{1}{4}, \frac{3}{4}, \frac{1}{4}\right)$, and four $\mathrm{X}^{-}$ anions located at the 4 a site $(0,0,0),\left(\frac{1}{2}, \frac{1}{2}, 1\right),\left(\frac{1}{2}, 1, \frac{1}{2}\right),\left(1, \frac{1}{2}, \frac{1}{2}\right)$, which corresponds to the experimentally observed structure of $\mathrm{Li}_{6} \mathrm{PS}_{5} \mathrm{I}$ in space group $F \overline{4} 3 m$. By swapping one pair of $\mathrm{Y}^{2-} / \mathrm{X}^{-}$ per unit cell, the degree of site-inversion is increased to $25 \%$. To study the effect of site-inversion more in detail, a four-fold supercell has been constructed for the model compound $\mathrm{Li}_{6} \mathrm{PS}_{5} \mathrm{Br}$, so that the model contains 16 pairs of swappable anions and the degree of site inversion can be modelled in steps of $6.25 \%$.

\section{Hydrolysis stability}

Hydrolysis stability of the lithium-containing sulphides is estimated by assuming the formation of the primary products $\mathrm{LiOH}$ and $\mathrm{H}_{2} \mathrm{~S}$. The calculation method is essentially the same as for evaluating structural stabilities. To identify the critical reaction of hydrolysis, it is assumed that an excess number $n$ of water molecules is available and the resulting hydrolysis products contain oxides. In the system $\mathrm{Li}-\mathrm{P}-\mathrm{S}-\mathrm{H}-\mathrm{O}$, the critical reaction is:

$$
\mathrm{Li}_{3} \mathrm{PS}_{4}+n \mathrm{H}_{2} \mathrm{O} \leftrightarrow 4 \mathrm{H}_{2} \mathrm{~S}+(n-4) \mathrm{H}_{2} \mathrm{O}+\mathrm{Li}_{3} \mathrm{PO}_{4}
$$

Eliminating the excess $\mathrm{H}_{2} \mathrm{O}$ on both sides leads to the final critical hydrolysis reaction:

$$
\mathrm{Li}_{3} \mathrm{PS}_{4}+4 \mathrm{H}_{2} \mathrm{O} \leftrightarrow 4 \mathrm{H}_{2} \mathrm{~S}+\mathrm{Li}_{3} \mathrm{PO}_{4}
$$

$¥$ The Wyckoff site names $4 \mathrm{~d}$ and $4 \mathrm{a}$ strictly speaking apply only to the most common case of space group $F \overline{4} 3 m$. For the lower symmetry cubic Argyrodites both sites would be of type $4 \mathrm{a}$, but still symmetry-independent. 
For many compounds hydrolysis reactions may consist of more than one reaction step. To simplify the simulation, the final products of hydrolysis are here consistently limited to the most basic products, e.g. $\mathrm{LiOH}$ instead of the corresponding hydrated $\mathrm{LiOH} \cdot x \mathrm{H}_{2} \mathrm{O}$.

In practice, hydrolysis reactions may be more complex. The products may e.g. be amorphous and non-stoichiometric, and the actual reaction path may depend on a number of factors such as humidity, temperature, and reaction time. Thus, the results presented in this study can only provide a rough guideline for comparing the relative (thermodynamic) hydrolysis stability of different argyrodites.

\section{Electronic conductivity}

To compare the electronic conductivities of the argyrodite phases, the bandgaps of the structures are calculated by DFT calculations using VASP. Since the employed GGA functional has the intrinsic tendency to underestimate the bandgap, the resulting values have to be understood as lower bounds to the true bandgaps.

\section{Pathway for and activation energy of ionic conductivity}

All cubic phases of argyrodites exhibit a three-dimensional network of pathways connecting partially occupied sites for the migration of the monovalent $\mathrm{A}^{+}$ions and hence show ionic conductivity. In this report the activation energy for ion migration is estimated as the main influencing factor. Our empirical bond-valence based softBV forcefield ${ }^{37}$ is used to analyse the site energies of $\mathrm{Li}^{+}$ions $E_{\mathrm{BVSE}}(\mathrm{Li})$ throughout the structures of lithium argyrodites. Migration pathways for $\mathrm{Li}^{+}$are then analysed as regions of low $E_{\mathrm{BVSE}}(\mathrm{Li})$ in the resulting grids spanning the structure model with a resolution of typically $(0.1 \AA)^{3}$, which has been demonstrated to be a simple and reliable way of identifying transport pathways in local structure models, ${ }^{29,30}$ provided that the local structure model captures the essential structural features. For the purpose of analyzing $E_{\mathrm{BVSE}}(\mathrm{Li})$ landscapes Coulomb repulsions are considered only between mobile and immobile cations (here e.g. $\mathrm{Li}^{+}-\mathrm{P}^{5+}$ ), while Coulomb attraction terms are generally integrated in the Morse attraction term. Starting from an analysis of local minima and saddle points of $E_{\mathrm{BVSE}}(\mathrm{Li})$, the grid analysis utilizes a modified Dewar, Healy and Stewart (DHS)-type path finding algorithm ${ }^{38}$ to identify low energy paths connecting the local site energy minima. ${ }^{39}$

Such energy landscapes based on rigid structure models without the possibility for structural relaxation inherently overestimate the energy barriers. In order to factor in the reduction of energy barriers by relaxation effects, the initially observed barriers needs to be scaled down by an empirical factor $\approx 0.5$ that slightly depends on both the mobile ion and on the anion in its first coordination shell. For details on the scaling factor see Table S1 in the ESI. $\dagger$ By means of this scaling, the scaled predicted activation energies should become comparable to each other and to experimental results, while unscaled activation energies can only be compared among compounds with similar compositions.

\section{Results and discussion}

\section{Substitution of $\mathbf{M}^{m+}$ and $\mathrm{X}^{-}$in $\mathbf{L i}_{12-x-m}\left(\mathbf{M}^{m+} \mathbf{S}_{4}\right) \mathbf{S}_{2-x} \mathbf{X}_{x}$}

Structural stability. In the lithium argyrodites $\mathrm{Li}_{7-x}\left(\mathrm{PS}_{4}\right) \mathrm{S}_{2-x} \mathrm{X}_{x}$, $\mathrm{P}^{5+}$ may be substituted by $\mathrm{As}^{5+}, \mathrm{Si}^{4+}, \mathrm{Ge}^{4+}$, or $\mathrm{Sn}^{4+}$ with lithium contents adjusted to the halide content $x$ and the charge of the respective high-valent cation $\mathbf{M}^{m+}$. When comparing the resulting compounds with respect to their structural stability, it turns out that all the $\mathrm{Li}_{12-x-m} \mathrm{M}^{m+} \mathrm{S}_{6-x} \mathrm{X}_{x}$ compounds share the same critical (decomposition) reaction expressed as eqn (5):

$$
\mathrm{Li}_{12-x-m} \mathrm{M}^{m+} \mathrm{S}_{6-x} \mathrm{X}_{x} \leftrightarrow \mathrm{Li}_{8-m} \mathrm{M}^{m+} \mathrm{S}_{4}+(2-x) \mathrm{Li}_{2} \mathrm{~S}+x \mathrm{LiX}
$$

The results summarised in Fig. 2 show that most of the argyrodites are metastable, and thus may only be synthesized with suitable non-equilibrium low-temperature methods, as they might decompose at higher temperatures. With increasing halogen content, the structural stability of the $\mathrm{NaHg}_{2}$-related orthorhombic phases is enhanced when compared to the argyrodite phases of the same composition. In other words, the calculations show that for $\mathrm{Li}_{6} \mathrm{MS}_{4} \mathrm{X}_{2}$ phases with $\mathrm{M}^{4+}$ cations the $\mathrm{NaHg}_{2}$-related structures are more stable than the argyrodite phases (see Fig. 2a). For the $\mathbf{M}^{5+}$ cations the overall tendency is the same, but for the halide-richest compositions $\mathrm{Li}_{5} \mathrm{MS}_{4} \mathrm{X}_{2}$ the dissociation energies of argyrodite and $\mathrm{NaHg}_{2}$ phases are closely similar (see Fig. 2b).

Compounds based on the heavier $\mathrm{M}^{m+}$ cations $\mathrm{As}^{5+}$ and $\mathrm{Sn}^{4+}$ are overall less stable than those with the lighter $\mathbf{M}^{m+}$ cations and the least stable compounds involve these heavy $\mathbf{M}^{+}$cations in combination with the lightest halide $\mathrm{X}^{-}=\mathrm{Cl}^{-}$, so that the thermal stability will be further reduced and it may become more difficult to synthesize and stabilize them. In line with this, it was e.g. found that while argyrodites with $\mathrm{M}=\mathrm{P}$ can be formed for $\mathrm{X}=\mathrm{Cl}, \mathrm{Br}$ or $\mathrm{I}$, for $\mathrm{M}=$ As only those with $\mathrm{X}=\mathrm{Br}$ and $\mathrm{I}$ can be synthesized. ${ }^{40}$ In terms of choices of halogen elements, argyrodite phases containing iodide are more stable than those containing bromide and chloride.

When considering the dependence of the structural stability of the $\mathrm{Li}_{12-x-m}\left(\mathrm{M}^{m+} \mathrm{S}_{4}\right) \mathrm{S}_{2-x} \mathrm{X}_{x}$ argyrodites on the halide content $x$, the dissociation energies shown in Fig. 2 as a function of halide content $x$ exhibit a clear maximum at $x=1$ for $\mathrm{M}^{4+}$ compounds (cf. solid lines in Fig. 2a), while among the $\mathrm{M}^{5+}$ compounds only those with $\mathrm{X}^{-}=\mathrm{I}^{-}$show a comparatively pronounced stability maximum. Therefrom it may be concluded that for these two groups of argyrodites a (near) stoichiometric composition with $x=1$ will be preferred (as also found experimentally for $\mathrm{Li}_{6} \mathrm{M}^{5+} \mathrm{S}_{5} \mathrm{I}$ argyrodites). ${ }^{10,19,40}$ For the $\mathrm{M}^{5+}$ argyrodites with the lighter halide anions $\mathrm{Br}^{-}$and $\mathrm{Cl}^{-}$the dissociation energy decreases slightly as $x$ increases from 0 to 1 (for the case of $\mathrm{M}=\mathrm{P}$ ) or is practically constant (for $\mathrm{M}=\mathrm{As}$ ). In these compounds the entropy influence may preferentially lead to non-stoichiometric compounds with compositions controlled by details of the sample preparation conditions. Such a behaviour is experimentally observed for $\mathrm{Li}_{7-x} \mathrm{MS}_{6-x} \mathrm{X}_{x}$ (with $\mathrm{M}=\mathrm{P}, \mathrm{X}=\mathrm{Cl}$ or $\mathrm{Br}$ and to some extent for $\mathrm{M}=\mathrm{As}, \mathrm{X}=\mathrm{Br}$, where only a slight deviation from stoichiometry is noted). ${ }^{10,21,40}$ 

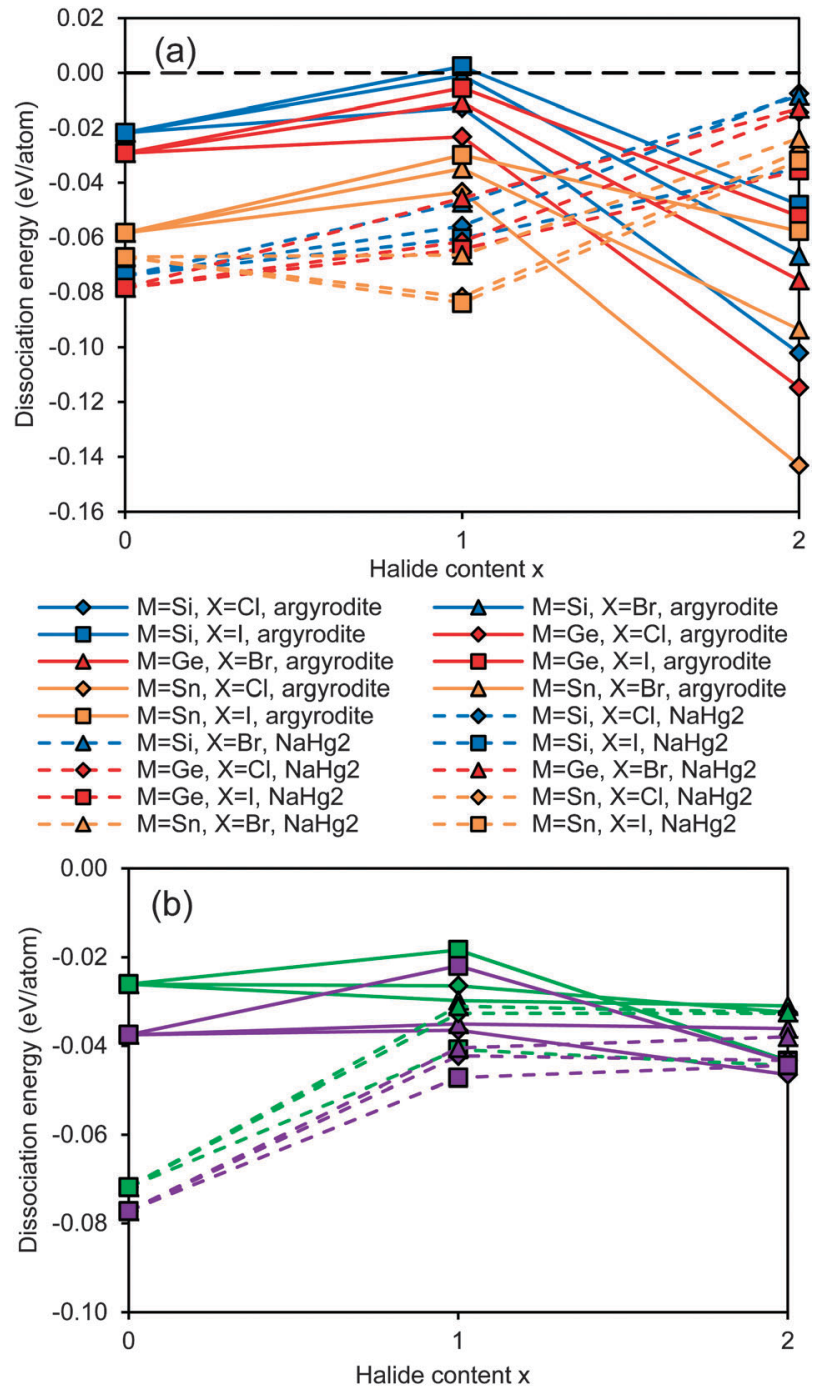

$\leadsto \mathrm{M}=\mathrm{P}, \mathrm{X}=\mathrm{Cl}$, argyrodite $\triangle \mathrm{M}=\mathrm{P}, \mathrm{X}=\mathrm{Br}$, argyrodite $\square-M=P, X=I$, argyrodite $\longrightarrow M=A s, X=C l$, argyrodite $\triangle \mathrm{M}=\mathrm{As}, \mathrm{X}=\mathrm{Br}$, argyrodite

$--\diamond-\mathrm{M}=\mathrm{P}, \mathrm{X}=\mathrm{Cl}, \mathrm{NaHg} 2$

$--\square-M=P, X=I, N a H g 2$

$--\Delta-M=A s, X=B r, N a H g 2$

$\longrightarrow \mathrm{M}=\mathrm{As}, \mathrm{X}=\mathrm{I}$, argyrodite

$--\Delta-M=P, X=B r, N a H g 2$

$-\diamond-\mathrm{M}=\mathrm{As}, \mathrm{X}=\mathrm{Cl}, \mathrm{NaHg} 2$

$--\square-\mathrm{M}=\mathrm{As}, \mathrm{X}=\mathrm{I}, \mathrm{NaHg} 2$

Fig. 2 Structural stability of (a) Si,Ge,Sn-argyrodites and (b) P,As-argyrodites. Higher positions in the graph indicate higher stability.

Even for stoichiometric argyrodites $\mathrm{Li}_{11-m} \mathrm{MS}_{5} \mathrm{X}$ (which are, as mentioned above, often close to the most preferable composition) the influence of disorder may be relevant for their structural stability. From earlier structural studies, it is known that e.g. in $\mathrm{Li}_{7-x} \mathrm{PS}_{6-x} \mathrm{X}_{x}$ with $\mathrm{X}=\mathrm{Cl}, \mathrm{Br}$ the experimentally observed $\mathrm{S}^{2-} / \mathrm{X}^{-}$anion distribution is disordered in the sense that there is a partial inversion between the occupancies of the nominal $\mathrm{S}^{2-}$ and $\mathrm{X}^{-}$sites. Detailed neutron diffraction studies indicate a temperature dependence of this disorder. ${ }^{21}$ Here we studied whether there is a thermodynamic driving force for the site inversion. Fig. 3 surveys the effect of site-inversion on the dissociation energies of the studied argyrodites with $x=1$. Swapping the occupancies of the four pairs of $\mathrm{S}^{2-} / \mathrm{X}^{-}$anions per unit cell allows varying the site occupancies in steps of $25 \%$.
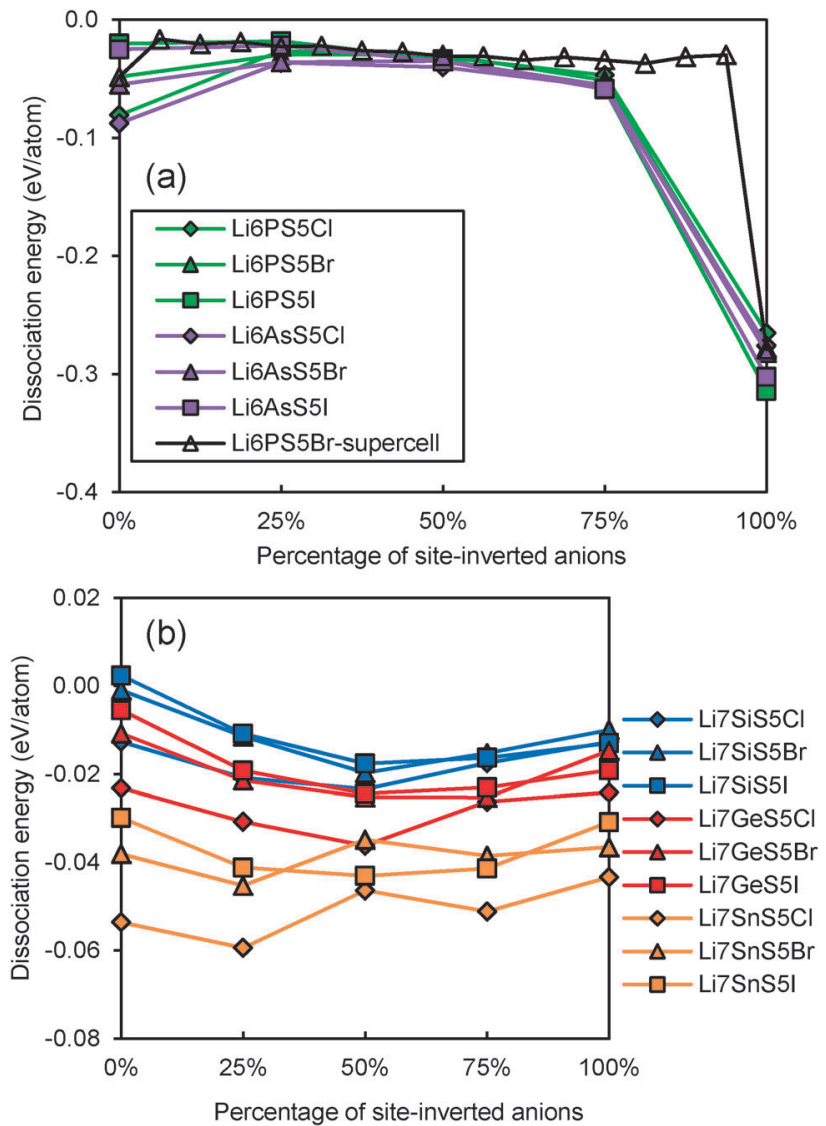

Fig. 3 Variation of dissociation energies of (a) P,As-argyrodites and (b) $\mathrm{Si}, \mathrm{Ge}, \mathrm{Sn}$-argyrodites with the degree of $\mathrm{S}^{2-} / \mathrm{X}^{-}$anion site-inversion.

From the results in Fig. 3 the effect of the $\mathrm{S}^{2-} / \mathrm{X}^{-}$site-inversion on the structural stability seems to depend on the oxidation state $m$ of the $\mathrm{M}^{m+}$ cation and the type of halogen atom involved. In argyrodites containing $\mathrm{M}^{5+}$ cations, chlorides and bromides prefer around $25 \%$ site-inversion while iodides prefer the fully ordered structure ( $0 \%$ site-inversion). This suggests that the experimentally observed site-inversion for $\mathrm{Li}_{6} \mathrm{PS}_{5} \mathrm{Cl}$ and $\mathrm{Li}_{6} \mathrm{PS}_{5} \mathrm{Br}$ (and fully ordered nature of the anion distribution in $\left.\mathrm{Li}_{6} \mathrm{PS}_{5} \mathrm{I}\right)$ is caused by an enthalpic driving force and not only a kinetic effect.

To understand more in detail the correlation between anion site-inversion and stability, configurations with random pairs of $\mathrm{S}^{2-} / \mathrm{Br}^{-}$swapped have also been calculated for a four-fold supercell in the case of $\mathrm{Li}_{6} \mathrm{PS}_{5} \mathrm{Br}$. Results are shown as open triangles in Fig. 3(a). Both fully ordered structures (no inversion or complete inversion) exhibit significantly more negative dissociation energy than the structures with partial $\mathrm{S}^{2-} / \mathrm{Br}^{-}$swapping. The dissociation energy reaches its least negative value for low degrees of site inversion (6-19\%) but show only a minute decrease towards higher degrees of site inversion before suddenly shooting down to the most negative value for the fully-inverted structure. The energies found for the same degrees of site inversion for the single cell and four-fold supercells of $\mathrm{Li}_{6} \mathrm{PS}_{5} \mathrm{Br}$ reasonably agree with each other, so that the fundamental variations for the other compounds may be estimated from the computationally 
less demanding single unit cell calculations in Fig. 3. In argyrodites containing $\mathrm{M}^{4+}$ cations (see Fig. 3(b)), the influence of site-inversion on structural stability is mostly reversed. Structures with $0 \%$ and $100 \%$ site-inversion are typically similar in dissociation energy and more stable than structures with $25-75 \%$ site-inversion. As mentioned above the compounds with $\mathbf{M}=$ Sn show the lowest stability independent of the site inversion and a less regular variation of the dissociation energy with the degree of anion site inversion.

Hydrolysis stability. In contrast to the discussion of structural stability above, the critical reactions for stability against hydrolysis are no longer the same for all argyrodites but depend on the choice of the cation $\mathrm{M}^{m+}$ according to eqn (6)-(10):

$$
\begin{gathered}
\mathrm{Li}_{7-x} \mathrm{PS}_{6-x} \mathrm{X}_{x}+(8-2 x) \mathrm{H}_{2} \mathrm{O} \leftrightarrow x \mathrm{LiX}+\mathrm{Li}_{3} \mathrm{PO}_{4} \\
+(6-x) \mathrm{H}_{2} \mathrm{~S}+(4-2 x) \mathrm{LiOH} \\
\mathrm{Li}_{7-x} \mathrm{AsS}_{6-x} \mathrm{X}_{x}+(7-2 x) \mathrm{H}_{2} \mathrm{O} \leftrightarrow x \mathrm{LiX}+0.5 \mathrm{As}_{2} \mathrm{~S}_{3}+\mathrm{S} \\
+(3.5-x) \mathrm{H}_{2} \mathrm{~S}+(7-2 x) \mathrm{LiOH} \\
\mathrm{Li}_{8-x} \mathrm{SiS}_{6-x} \mathrm{X}_{x}+(9-2 x) \mathrm{H}_{2} \mathrm{O} \leftrightarrow x \mathrm{LiX}+\mathrm{Li}_{2} \mathrm{SiO}_{3} \\
+(6-x) \mathrm{H}_{2} \mathrm{~S}+(6-2 x) \mathrm{LiOH} \\
\mathrm{Li}_{8-x} \mathrm{GeS}_{6-x} \mathrm{X}_{x}+(8-2 x) \mathrm{H}_{2} \mathrm{O} \leftrightarrow x \mathrm{LiX}+\mathrm{GeS}_{2} \\
+(4-x) \mathrm{H}_{2} \mathrm{~S}+(8-2 x) \mathrm{LiOH} \\
\mathrm{Li}_{8-x} \mathrm{SnS}_{6-x} \mathrm{X}_{x}+(8-2 x) \mathrm{H}_{2} \mathrm{O} \leftrightarrow x \mathrm{LiX}+\mathrm{SnS}_{2} \\
+(4-x) \mathrm{H}_{2} \mathrm{~S}+(8-2 x) \mathrm{LiOH}
\end{gathered}
$$

When comparing the resulting hydrolysis stability values for $\mathrm{Li}_{12-x-m} \mathrm{M}^{m+} \mathrm{S}_{6-x} \mathrm{X}_{x}$ argyrodites in Fig. 4 it becomes obvious that all these lithium argyrodites will decompose in contact with water, as indicated by the negative dissociation energies. Phosphorus and silicon argyrodites are highly sensitive to moisture (with the commonly studied P-compounds typically being the worst case in terms of hydrolysis stability), while germanium, tin and arsenic argyrodites are significantly less vulnerable to hydrolysis. It should however be kept in mind that the latter two also have a lower structural stability. In terms of the halide content, compounds without any halogen atoms

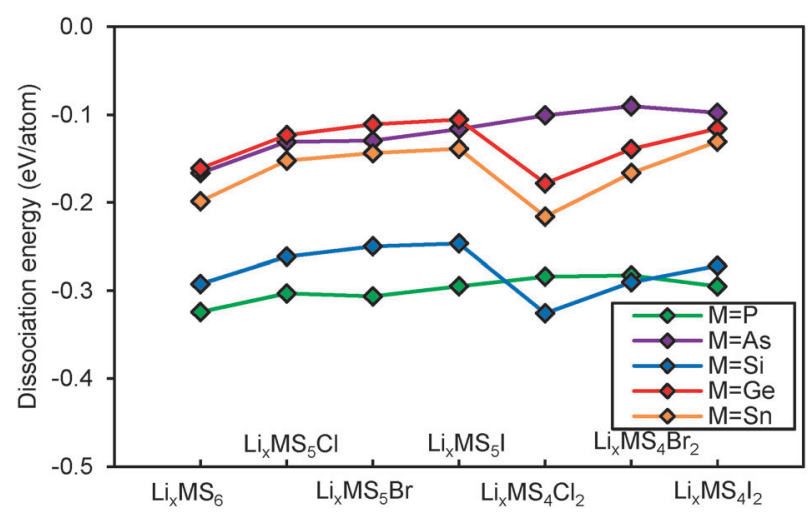

Fig. 4 Hydrolysis dissociation energy of argyrodites with different halide contents. Compounds containing the same cation $M(M=P, A s, S i, G e, S n)$ are connected by lines as a guide to the eye.
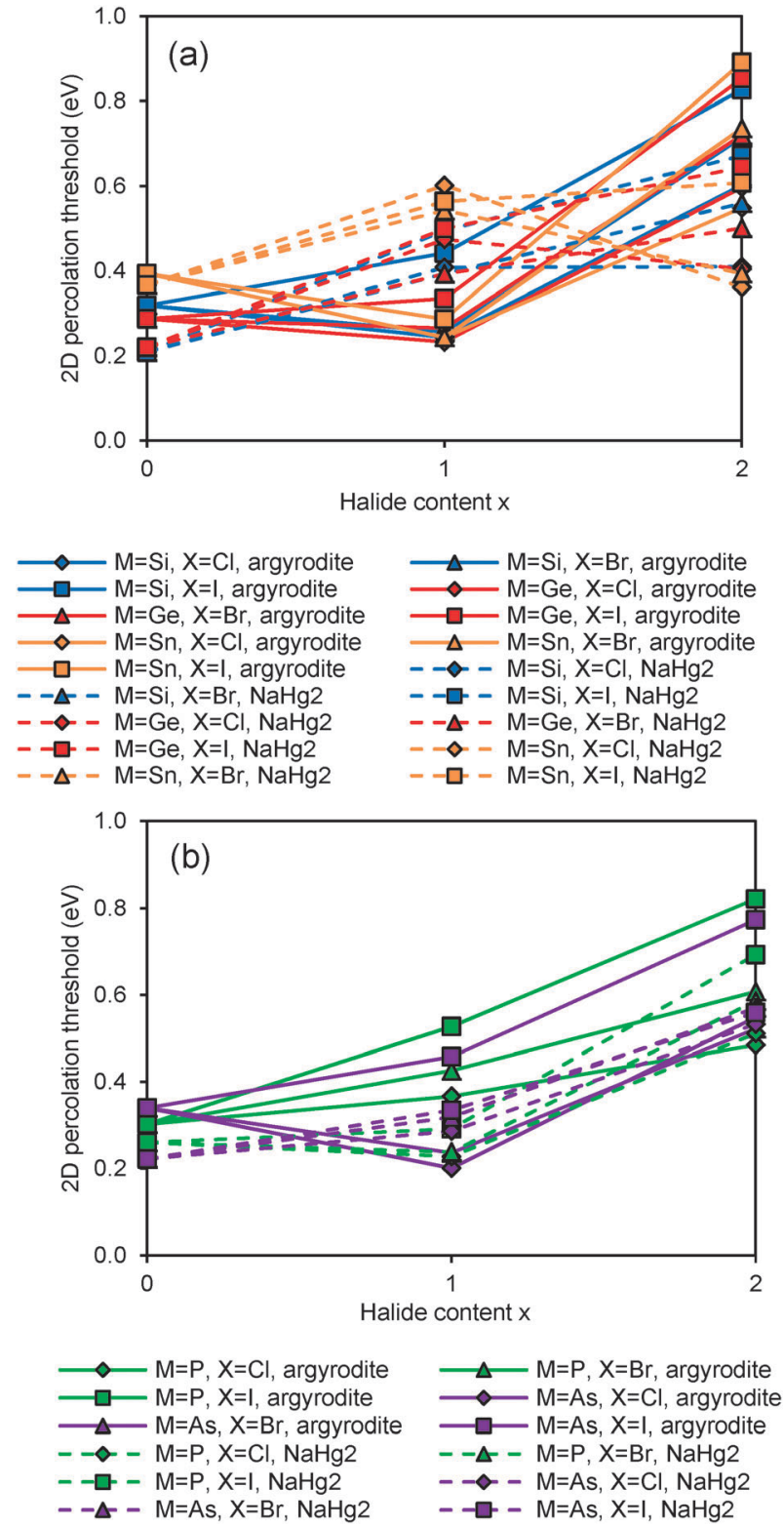

Fig. 5 Comparison of activation energies required for $\mathrm{Li}^{+}$motion in 2D percolating pathways in geometry-optimised models of various argyrodites and $\mathrm{NaHg}_{2}$-related phases: (a) Si,Ge,Sn-compounds and (b) P,As-compounds. Fully ordered argyrodite structure models ( $0 \%$ anion site-inversion) are used consistently in these activation energy calculations.

demonstrate lower hydrolysis stability, and the vulnerability to hydrolysis only slightly decreases with the increase of the size of the halogen atom among the $\mathrm{Li}_{11-m} \mathrm{M}^{m+} \mathrm{S}_{5} \mathrm{X}$ argyrodites with the same halide content.

Activation energy for $\mathbf{L i}^{+}$migration. Fig. 5 compares the activation energies for $\mathrm{Li}^{+}$migration in the compounds containing various $\mathrm{M}^{m+}$ cations as derived from our bond-valence based site energy mapping. For the sake of simplicity this comparison is based on the fully anion-ordered argyrodite structure models. It should also be noted that the DFT geometry optimisation will lead to some deviation of the unit cell volume from the experimentally observed room temperature values 
limiting the accuracy of the activation energy prediction while semiquantitative trends should be preserved. The cubic or pseudocubic argyrodites are obviously 3D conductors so that also for the $a b$ initio geometry-optimised local structure models (formally in space group $P 1$ ) the percolation thresholds for 1D, 2D and 3D long-range $\mathrm{Li}^{+}$ion migration differ only minutely. In contrast, the $\mathrm{NaHg}_{2}$-related phases are essentially 2D ionic conductors where the migration perpendicular to the fast-ionconducting planes requires significantly higher activation energy than within the planes.

$\mathrm{Li}^{+}$migration in argyrodites $\mathrm{Li}_{12-m} \mathrm{M}^{m+} \mathrm{S}_{6}$ and $\mathrm{Li}_{11-m} \mathrm{M}^{m+} \mathrm{S}_{5} \mathrm{X}$ requires lower activation energies than in halide-rich argyrodites $\mathrm{Li}_{10-m} \mathrm{M}^{m+} \mathrm{S}_{4} \mathrm{X}_{2}$. Moreover argyrodites containing $\mathrm{I}^{-}$tend to have higher activation energies than those containing $\mathrm{Cl}^{-}$and $\mathrm{Br}^{-}$in line with a more general rough trend that the more stable (anion ordered) compounds tend to show somewhat higher activation energies also for the $\mathrm{Li}^{+}$mobility. In addition, the lower repulsion of $\mathrm{M}^{4+}$ and higher concentration of mobile charge carriers seems to favour on average somewhat lower activation energies in $\mathrm{Li}_{7} \mathrm{M}^{4+} \mathrm{S}_{5} \mathrm{X}$ than in $\mathrm{Li}_{6} \mathrm{M}^{5+} \mathrm{S}_{5} \mathrm{X}$ compounds. Moreover, $\mathrm{NaHg}_{2}$-related $\mathrm{Li}_{7} \mathrm{M}^{4+} \mathrm{S}_{5} \mathrm{X}$ phases are found to have higher (and the $\mathrm{Li}_{6} \mathrm{M}^{4+} \mathrm{S}_{5} \mathrm{X}_{2}$ compounds lower) activation energies than the argyrodites of the same composition, while for the phases containing $\mathrm{M}^{5+}$ no such systematic difference between the two structure types can be observed in terms of their activation energy for $\mathrm{Li}^{+}$migration. The influence of the $\mathrm{S}^{2-} / \mathrm{Br}^{-}$anion site-inversion in local supercell structure models of the $\mathrm{Li}_{6} \mathrm{PS}_{5} \mathrm{Br}$ on the predicted activation energy barrier for $\mathrm{Li}^{+}$is demonstrated in Fig. 6. Configurations of $100 \%, 50 \%$ and $0 \%$ site-inversion are found to have the smallest activation energies. The specific choice of local structures may affect this finding. Still, the observation that the difference in activation energy between the highest and lowest activation energy configurations for the same composition reaches about $0.20 \mathrm{eV}$ suggests that anion disorder in argyrodites strongly influences the local and overall lithium ion conductivity.

To assess the accuracy of the empirical approach for estimating migration barriers from structure models using the softBV forcefield, experimental activation energy data from the literature conductivity and NMR studies are compared to the calculated migration barriers. ${ }^{16,41-45}$ While local structures generated from

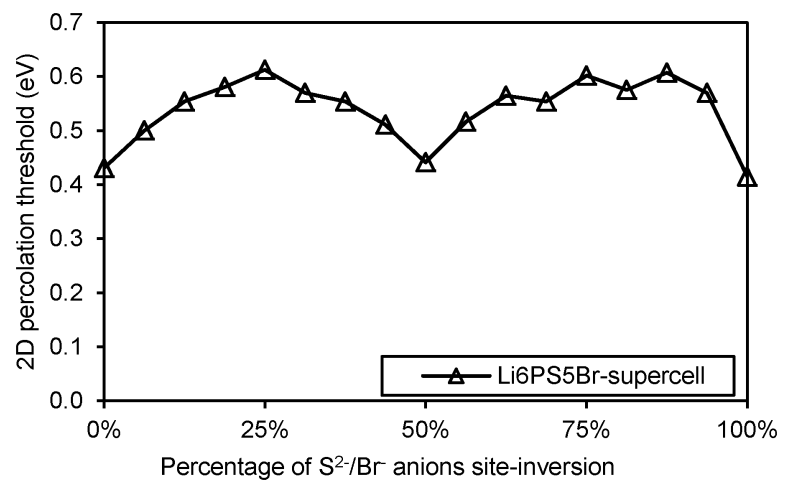

Fig. 6 Activation energy required for $\mathrm{Li}^{+}$migration in site-inverted configurations of $\mathrm{Li}_{6} \mathrm{PS}_{5} \mathrm{Br}$ supercell.

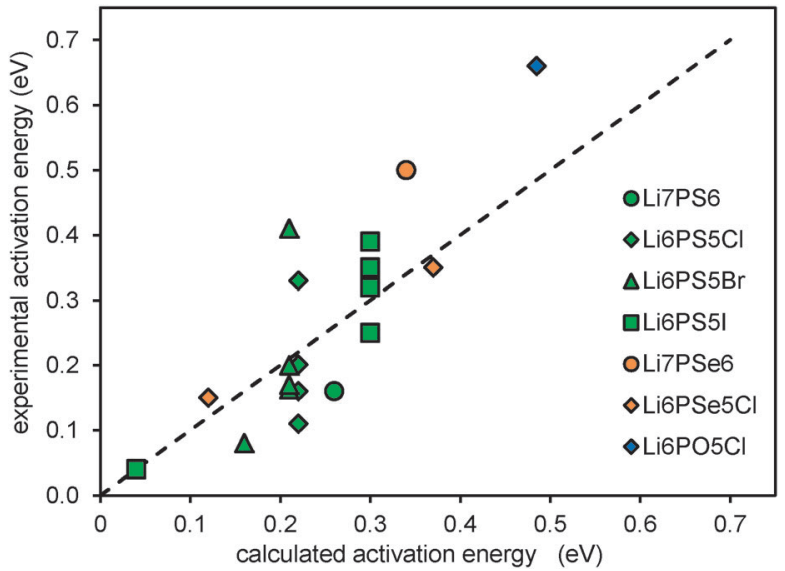

Fig. 7 Comparison of experimental activation energies to calculated activation energies based on experimentally determined structures.

DFT geometry-optimisation do not readily accommodate fractional occupancy and show some deviation in lattice parameters compared to experimentally determined structures, these comparisons are based on experimental structure data., ${ }^{10,40,46}$ Results are summarised in Fig. 7. It should be noted that among the calculated barrier energies values $<0.2 \mathrm{eV}$ refer to barriers for local hopping and the corresponding experimental data are NMR data, while values $>0.2 \mathrm{eV}$ correspond to the migration barrier for percolating pathways. As seen from Fig. 7 the limiting factor for the quality of the correlation is less the quality of the computational prediction but the large spread in the experimental activation energies reported in the literature for the same compound.

$\mathrm{Li}^{+}$ions in argyrodites are generally found to be distributed over three types of sites. Site A ( $48 \mathrm{~h}$ ) refers to the equilibrium site that hosts the bulk of $\mathrm{Li}^{+}$ions in all argyrodite structures. Interstitial sites of type B (48 h) are located in-between A sites, so that $3 \mathrm{~A}$ and $3 \mathrm{~B}$ sites nearly form a low energy pathway hexagon. In combination with local paths connecting directly two A sites 4 such A-B hexagons form a local pathway cage around each $\mathrm{S}^{2-}$ anion in $\mathrm{Li}_{6} \mathrm{PS}_{5} \mathrm{I}$. The $\mathrm{A}$ sites in these cages are then connected via type $\mathrm{C}$ interstitial sites (16e) to a 3-dimensional migration pathway network. In $\mathrm{Li}_{6} \mathrm{PSe}_{5} \mathrm{Cl}$ the local $(\mathrm{A}-\mathrm{B})_{3}$ pathway hexagons are bridged by $\mathrm{A}-\mathrm{C}-\mathrm{A}$ pathways to local pathway cages around the halide ion that only for higher activation energies merge to a percolating pathway network by direct A-A bridges.

The relative site energies and activation barriers between sites are summarised in Fig. 8, in which the lowest site energy among the three types of sites is set to $0 \mathrm{eV}$. The percolation threshold (or the long-range activation energy) equals to the maximum of the three relevant migration barriers, i.e. either the barrier between two A sites or between an A site and a $\mathrm{C}$ site. It may also be noted that their respective barrier heights are anticorrelated. $\mathrm{Li}_{6} \mathrm{PS}_{5} \mathrm{I}$, for example, shows a very low activation energy between two A sites which may correspond to the experimentally observed short-range activation energy of $0.04 \mathrm{eV}$, but the much larger activation energy between A and C sites causes the relatively high activation energy of about 


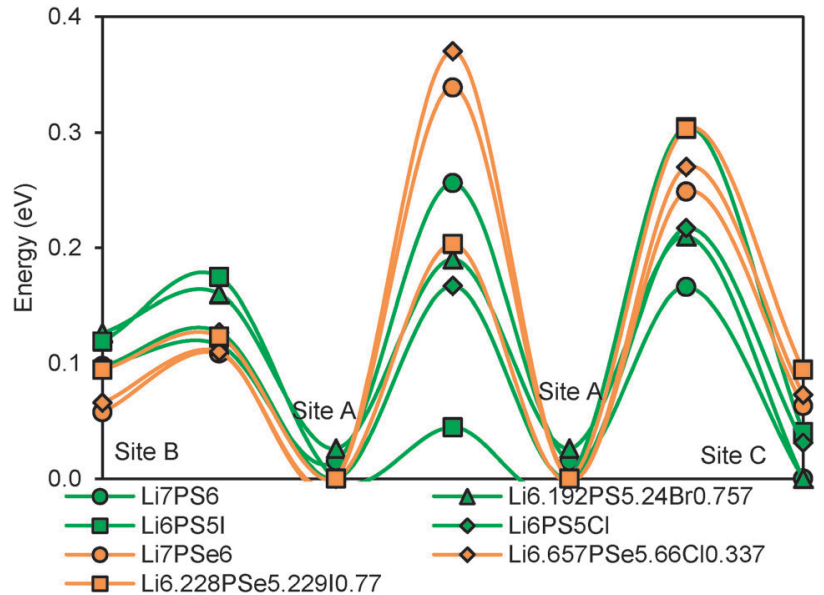

Fig. 8 Site energies and activation barriers between neighbouring sites in sulphide and selenide argyrodites.

$0.35 \mathrm{eV}$ for dc conductivity. ${ }^{44}$ When the size of the halide ion is reduced by substituting $\mathrm{I}^{-}$by $\mathrm{Br}^{-}$the $\mathrm{A}-\mathrm{C}$ barrier shrinks and the A-A barrier increases so that the activation energy for local motions slightly increases, while the activation energy for $\mathrm{dc}$ conductivity is considerably reduced.

To study the effect of anion disorder on the migration barriers between the different sites, we analysed the barriers in hypothetical structures derived from the experimental structure of $\mathrm{Li}_{6} \mathrm{PS}_{5} \mathrm{Br}$. A fully stoichiometric and anion ordered structure is compared to structures with mixed anion site occupancy, where in steps of 0.25 increasing fractions of $\mathrm{Br}^{-}$are assigned to the $4 \mathrm{~d}$ sites, while the corresponding amount of $\mathrm{S}^{2-}$ is redistributed to the $4 \mathrm{a}$ sites. The effect of the different degrees of anion disorder on the migrations barriers in $\mathrm{Li}_{6} \mathrm{PS}_{5} \mathrm{Br}$ are summarized in Fig. 9. The increase in anion disorder has little effect on the height of the migration barrier between A and B sites, but consistently increases barrier heights between two A sites and decreases activation energies between $\mathrm{A}$ and $\mathrm{C}$ sites. For the case of $\mathrm{Li}_{6} \mathrm{PS}_{5} \mathrm{Br}$ the lowest activation energy for long-range ion migration (dc conductivity) results for $25 \%$ anion disorder, when the barrier heights for $\mathrm{A}-\mathrm{A}$ and $\mathrm{A}-\mathrm{C}$ hops are almost equal.

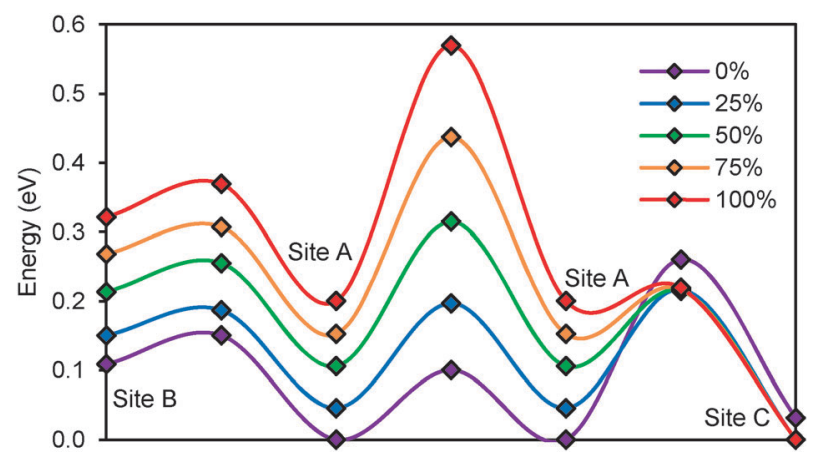

Fig. 9 Site energies and activation barriers between neighbouring sites in $\mathrm{Li}_{6} \mathrm{PS}_{5} \mathrm{Br}$ with different degree of anion disordering. $0 \%$ refers to the fully ordered structure corresponding to the experimental structure of $\mathrm{Li}_{6} \mathrm{PS}_{5} \mathrm{I}$.
Selection guidelines. To select a structure with suitable properties for application as solid electrolyte, the requirement of low activation energy for lithium ion migration effectively limits the choices to the $\mathrm{Li}_{11-m} \mathrm{M}^{m+} \mathrm{S}_{5} \mathrm{X}$ compounds with $\mathrm{X}=\mathrm{Cl}$ and $\mathrm{Br}$ or the halide-free $\mathrm{Li}_{12-m} \mathrm{M}^{m+} \mathrm{S}_{6}$. Among these compounds, the structural stability of the argyrodite phases is higher than the one of the corresponding $\mathrm{NaHg}_{2}$-related phases. Further examination on their dissociation energies suggests that the argyrodites with $\mathrm{M}=\mathrm{P}$, Ge and Si have higher stability, and structures with halide content $\left(\mathrm{Li}_{11-m} \mathrm{M}^{m+} \mathrm{S}_{5} \mathrm{X}\right)$ are more stable than those without $\left(\mathrm{Li}_{12-m} \mathrm{M}^{m+} \mathrm{S}_{6}\right)$. The halide content also somewhat mitigates the vulnerability to hydrolysis. Especially the germanium compounds show more favourable relative hydrolysis stability. In summary, except for the known $\mathrm{Li}_{6} \mathrm{PS}_{5} \mathrm{X}$ and $\mathrm{Li}_{7} \mathrm{PS}_{6}$ compounds, the most promising candidates in the search for lithium-ion conducting compounds with technically interesting properties would be $\mathrm{Li}_{7} \mathrm{GeS}_{5} \mathrm{X}, \mathrm{Li}_{7} \mathrm{SiS}_{5} \mathrm{X}, \mathrm{Li}_{8} \mathrm{GeS}_{6}$ and $\mathrm{Li}_{8} \mathrm{SiS}_{6}$ where $\mathrm{X}=\mathrm{Cl}$ or $\mathrm{Br}$.

\section{Substitution of $\mathrm{A}^{+}$and $\mathrm{X}^{-}$in $\mathrm{A}_{7-x}\left(\mathrm{PS}_{4}\right) \mathrm{S}_{2-x} \mathrm{X}_{x}$ argyrodites}

Structural stability. Lithium ions in lithium argyrodites can be substituted by a number of monovalent cations. Here the lithium compounds are compared to the previously known copper argyrodites and possible analogous sodium argyrodites due to the lower cost and higher earth abundance of sodium compared to lithium.

Critical reactions for structural stability are given in eqn (5), (11) and (12) for $\mathrm{A}=\mathrm{Li}, \mathrm{Na}$ or $\mathrm{Cu}$, respectively:

$$
\begin{gathered}
\mathrm{Na}_{7-x} \mathrm{PS}_{6-x} \mathrm{X}_{x} \leftrightarrow x \mathrm{NaX}+(2-x) \mathrm{Na}_{2} \mathrm{~S}+\mathrm{Na}_{3} \mathrm{PS}_{4} \\
\mathrm{Cu}_{7-x} \mathrm{PS}_{6-x} \mathrm{X}_{x} \leftrightarrow x \mathrm{CuX}+(0.5-0.25 x) \mathrm{Cu} \\
+(0.5-0.25 x) \mathrm{Cu}_{7} \mathrm{~S}_{4}+\mathrm{Cu}_{3} \mathrm{PS}_{4}
\end{gathered}
$$

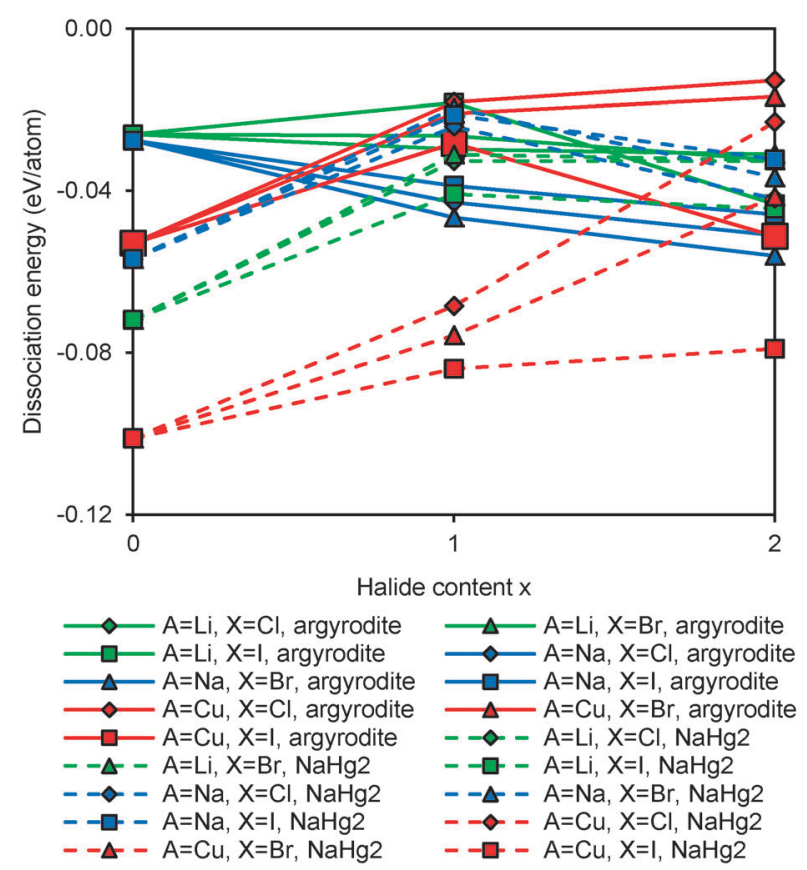

Fig. 10 Structural stability of compounds containing $\mathrm{A}^{+}=\mathrm{Li}^{+}, \mathrm{Na}^{+}$and $\mathrm{Cu}^{+}$. 


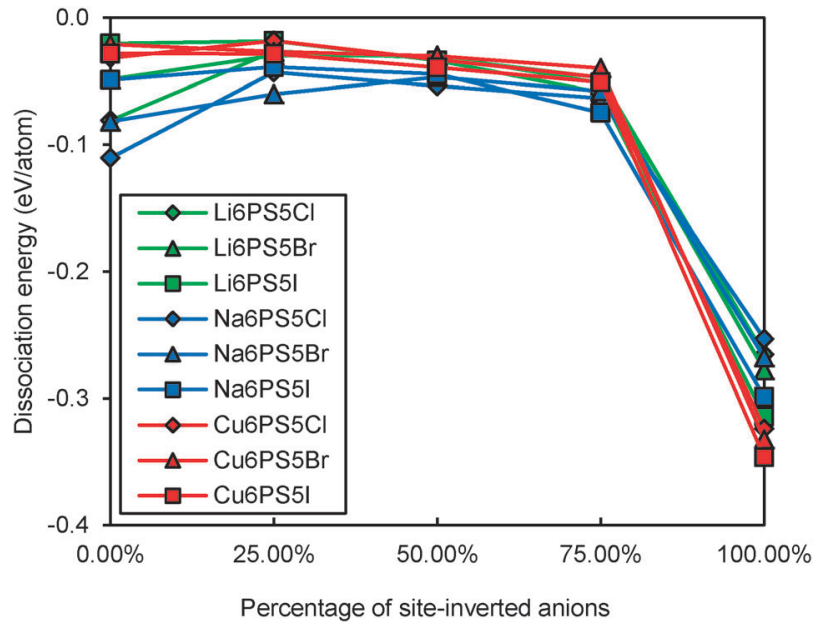

Fig. 11 Effect of anion site-inversion on the dissociation energy of A-argyrodites.

Fig. 10 compares the structural stability of compounds containing different mobile cations $\mathrm{A}^{+}$. Sodium argyrodites are found to be less stable than lithium and copper argyrodites, consistent with the fact that most of the discovered argyrodites contain copper, silver and lithium instead of sodium. From Fig. $10, \mathrm{Na}_{7} \mathrm{PS}_{6}$ may be the only practically accessible sodium argyrodite phase. Among the studied phases copper argyrodites are found to be the most stable, in line with the existence of natural copper-containing argyrodite $\mathrm{Ag}_{3.48} \mathrm{Cu}_{4.68} \mathrm{GeS}_{6}$ in minerals. ${ }^{47}$ Copper argyrodites are always more stable than the $\mathrm{NaHg}_{2}$-related phases of the same composition. Similar to $\mathrm{Li}_{6} \mathrm{PS}_{5} \mathrm{I}$ and in line with experimental structure determinations, $\mathrm{Cu}_{6} \mathrm{PS}_{5} \mathrm{I}$ is expected to be stoichiometric from the pronounced stability maximum around $x=1 .^{48,49}$

Again we explored possible effects of anion site site-inversion on stability of A-argyrodites and the findings are summarized in Fig. 11. The overall shapes of the stability vs. degree of site inversion curves are similar for all three types of compounds: with the increase in size of halogen anions (and thus in the $\mathrm{X}^{-}$ sulphide size difference), the most stable degree of site-inversion shifts from $25 \%$ towards $0 \%$. Argyrodites containing $\mathrm{I}^{-}$always prefer the fully ordered configuration. This suggests that the nature of the $\mathrm{A}^{+}$ion has only a minor influence on the preferable degree of site inversion.

Hydrolysis stability. Critical reactions for hydrolysis stability are given in eqn (6), (13) and (14) for $\mathrm{A}=\mathrm{Li}, \mathrm{Na}$ or $\mathrm{Cu}$, respectively:

$$
\begin{gathered}
\mathrm{Na}_{7-x} \mathrm{PS}_{6-x} \mathrm{X}+(8-2 x) \mathrm{H}_{2} \mathrm{O} \leftrightarrow x \mathrm{NaX}+\mathrm{Na}_{3} \mathrm{PO}_{4} \\
+(6-x) \mathrm{H}_{2} \mathrm{~S}+(4-2 x) \mathrm{NaOH}
\end{gathered}
$$

$$
\begin{gathered}
\mathrm{Cu}_{7-x} \mathrm{PS}_{6-x} \mathrm{X}_{x}+5 / 32(2-x) \mathrm{H}_{2} \mathrm{O} \leftrightarrow x \mathrm{CuX}+1 / 32(2-x) \mathrm{P}_{2} \mathrm{O}_{5} \\
+1 / 16(14+x) \mathrm{Cu}_{3} \mathrm{PS}_{4}+5 / 16(2-x) \mathrm{Cu}_{7} \mathrm{~S}_{4}+5 / 32(2-x) \mathrm{H}_{2}
\end{gathered}
$$

Fig. 12 shows the relative stability against moisture of compounds containing the three types of mobile $\mathrm{A}^{+}$cations.

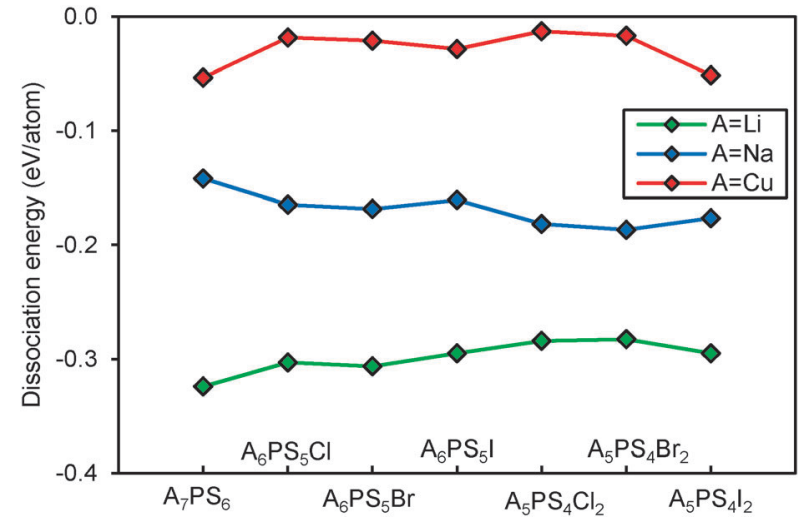

Fig. 12 Comparison of hydrolysis stability of argyrodites containing different $\mathrm{A}^{+}$cations.

Argyrodites containing copper are much more stable to moisture than the alkali argyrodites. This is because copper sulphide $\left(\mathrm{Cu}_{7} \mathrm{~S}_{4}\right)$ and copper thiophosphate $\left(\mathrm{Cu}_{3} \mathrm{PS}_{4}\right)$ are more stable than their lithium and sodium counterparts in water. The predicted decomposition reaction of copper argyrodites would thus release $\mathrm{H}_{2}$ rather than $\mathrm{H}_{2} \mathrm{~S}$ (as released by $\mathrm{Li}$ and $\mathrm{Na}$ argyrodites) and the released amount is much smaller compared to that of $\mathrm{H}_{2} \mathrm{~S}$ in the case of the alkali. The higher hydrolysis stability of sodium argyrodites compared to lithium argyrodites is less intuitive. It may be affected by our approach of limiting ourselves to the primary reaction products $\mathrm{AOH}$ and hydrogen-free A oxides. Both of them will further react with water and the reaction energy depends largely on element A.

Activation energy for $\mathrm{A}^{+}$migration. From the overview of activation energies for $\mathrm{A}^{+}$motion in Fig. 13 it can be seen that sodium compounds overall demonstrate lower activation energy

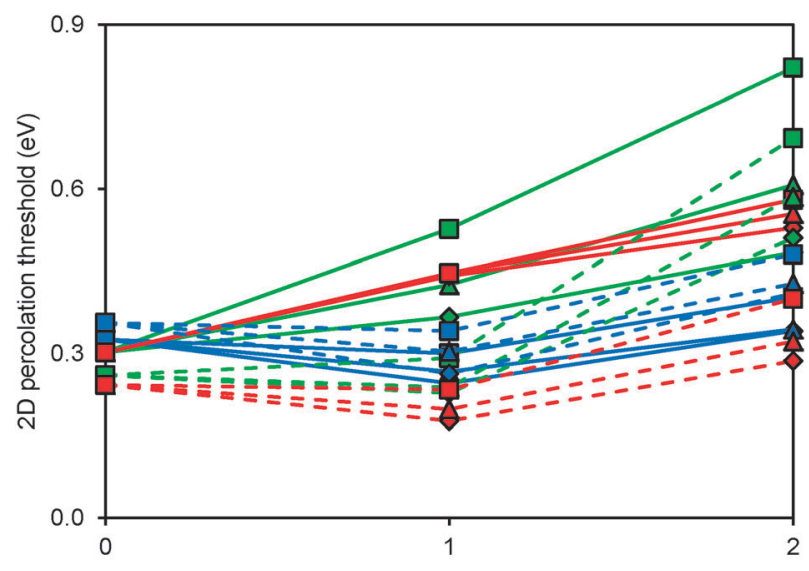

Halide content $x$

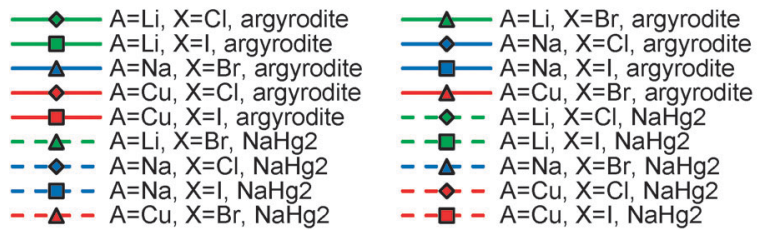

Fig. 13 Activation energies required for $\mathrm{A}^{+}$migration where $\mathrm{A}^{+}=\mathrm{Li}^{+}, \mathrm{Na}^{+}$ and $\mathrm{Cu}^{+}$as a function of the halide content. 
than lithium and copper compounds, but due to the instability of these structures the knowledge of the low activation energy may be of limited usefulness, and only $\mathrm{Na}_{7} \mathrm{PS}_{6}$ may be practically accessible. Copper argyrodites have similar level of activation energies compared to $\mathrm{Li}_{6} \mathrm{PS}_{5} \mathrm{Br}$, and the type of halide atoms seems to affect the activation energies of copper argyrodites much less than for their alkali counterparts. The activation energies of copper argyrodites show almost linear dependence on halide content $x$, which is a characteristic shared by lithium argyrodites. Although $\mathrm{NaHg}_{2}$-related copper compounds seem to be much more conductive than the argyrodite structures of the same composition, stability calculations (see Fig. 10) indicate that they are much harder to form than the argyrodite structures.

Selection guidelines. Judging from the low activation energy and the high concentration of mobile cations and free sites in the robust 3D network of migration pathways in lithium and copper argyrodites both will show reasonably high conductivity and (meta)stability. The alternative of sodium-ion conducting argyrodites appears less attractive as sodium argyrodites (except for $\mathrm{Na}_{7} \mathrm{PS}_{6}$ ) are unstable, and the predicted activation energy for $\mathrm{Na}_{7} \mathrm{PS}_{6}$ is slightly higher than for $\mathrm{Li}_{7} \mathrm{PS}_{6}$ (while in general the fast sodium-ion conducting solids can reach considerably lower activation energies than the best known $\mathrm{Li}^{+}$-ion conductors).

\section{Substitution of $\mathrm{Y}^{2-}$ and $\mathrm{X}^{-}$in $\mathrm{Li}_{7-x}\left(\mathrm{PY}_{4}\right) \mathrm{Y}_{2-x} \mathrm{X}_{x}$ argyrodites}

Structural stability. Softer anions are expected promote ionic conductivity, which is why the sulphide-based solid electrolytes generally reach higher conductivities than oxide-based ones. This invites the idea that selenium and tellurium argyrodites should show even higher ionic conductivity. However, their stability may be limited and electronic conductivity due to the increase of electron density may prevent their use as solid electrolytes. For comparison, two types of experimentally known oxygen argyrodites (with low ionic conductivity) will also be investigated. ${ }^{45}$

Critical reactions for structural stability are determined as eqn (5) and (15)-(19):

$$
\begin{gathered}
\mathrm{Li}_{6} \mathrm{PO}_{5} \mathrm{X} \leftrightarrow \mathrm{LiCl}+\mathrm{Li}_{2} \mathrm{O}+\mathrm{Li}_{3} \mathrm{PO}_{4} \\
\mathrm{Li}_{7} \mathrm{PSe}_{6} \leftrightarrow 2 \mathrm{Li}_{2} \mathrm{Se}+\mathrm{Li}_{3} \mathrm{PSe}_{4} \\
\mathrm{Li}_{6} \mathrm{PSe}_{5} \mathrm{X} \leftrightarrow 0.5 \mathrm{Se}+1.5 \mathrm{Li}_{2} \mathrm{Se}+\mathrm{LiX}+0.5 \mathrm{Li}_{4} \mathrm{P}_{2} \mathrm{Se}_{6} \\
\mathrm{Li}_{5} \mathrm{PSe}_{4} \mathrm{X}_{2} \leftrightarrow 0.5 \mathrm{Se}+0.5 \mathrm{Li}_{2} \mathrm{Se}+2 \mathrm{LiX}+0.5 \mathrm{Li}_{4} \mathrm{P}_{2} \mathrm{Se}_{6} \\
\mathrm{Li}_{7-x} \mathrm{PTe}_{6-x} \mathrm{X}_{x} \leftrightarrow x \mathrm{LiX}+\mathrm{P}+2.5 \mathrm{Te}+(3.5-x) \mathrm{Li}_{2} \mathrm{Te}
\end{gathered}
$$

Fig. 14 shows the dissociation energy of compounds containing different $\mathrm{Y}^{2-}$ anions. The structural stability of lithium argyrodites containing $\mathrm{Y}^{2-}$ increases in the order of $\mathrm{Te}<\mathrm{Se}<$ $\mathrm{S}<\mathrm{O}$. The tellurium compounds show considerably more negative dissociation energies indicating that they may practically not be accessible. Selenium compounds, on the other hand, have similar dissociation energies to those of sulphur compounds. Except for $\mathrm{Li}_{7} \mathrm{PSe}_{6}$ which has been successfully synthesized in the argyrodite structure, ${ }^{46}$ the likelihood for selenium compounds containing halogen elements to crystallize in argyrodite phase and $\mathrm{NaHg}_{2}$-related phase are almost equal.
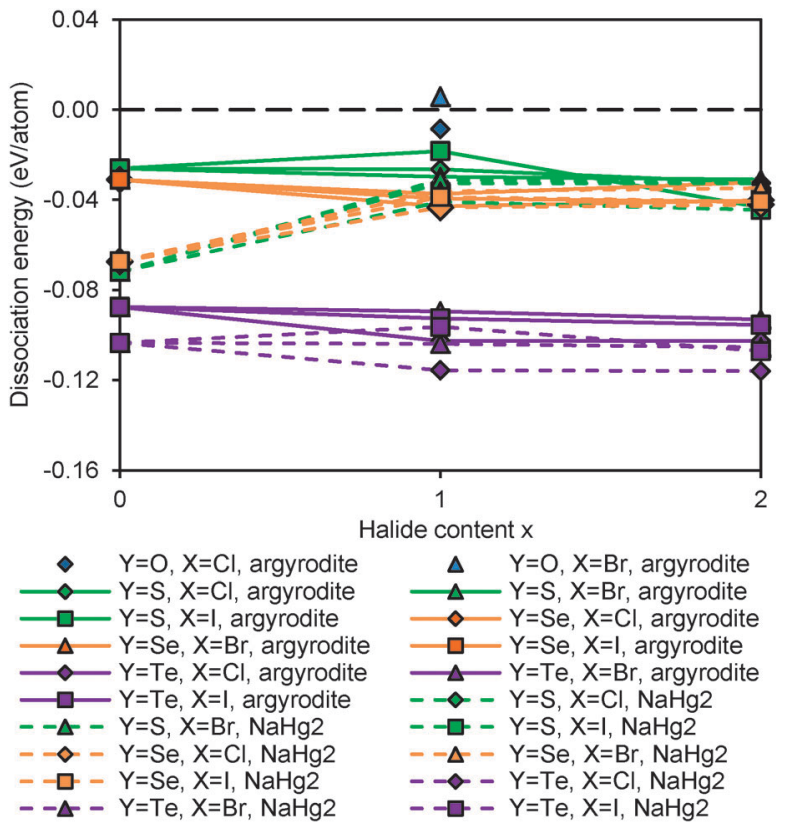

Fig. 14 Structural stability of compounds containing anions $\mathrm{Y}^{2-}=\mathrm{O}^{2-}$, $\mathrm{S}^{2-}, \mathrm{Se}^{2-}$ and $\mathrm{Te}^{2-}$.

It should be stressed that the critical reaction of selenium argyrodites takes only three $\mathrm{Li}-\mathrm{P}-\mathrm{Se}$ ternary compounds into consideration. Two of them are $\mathrm{Li}_{4} \mathrm{P}_{2} \mathrm{Se}_{6}{ }^{50}$ and $\mathrm{Li}_{7} \mathrm{PSe}_{6}$ as reported in a study by Francisco. ${ }^{51}$ Another compound $\mathrm{Li}_{4} \mathrm{PSe}_{3}$ is constructed by replacing sulphur atoms in $\mathrm{Li}_{3} \mathrm{PS}_{4}$ with selenium atoms. $\mathrm{Li}_{4} \mathrm{P}_{2} \mathrm{Se}_{6}$ is found to be the most stable ternary compound calculated so far. With the addition of new compounds into the phase Li-P-Se diagram, the critical reaction may change and the dissociation energy may become more negative. For all the different chalcogenide compounds studied the argyrodite phases are significantly preferred over $\mathrm{NaHg}_{2}$-related phases in the absence of halide anions, while for the halide-containing

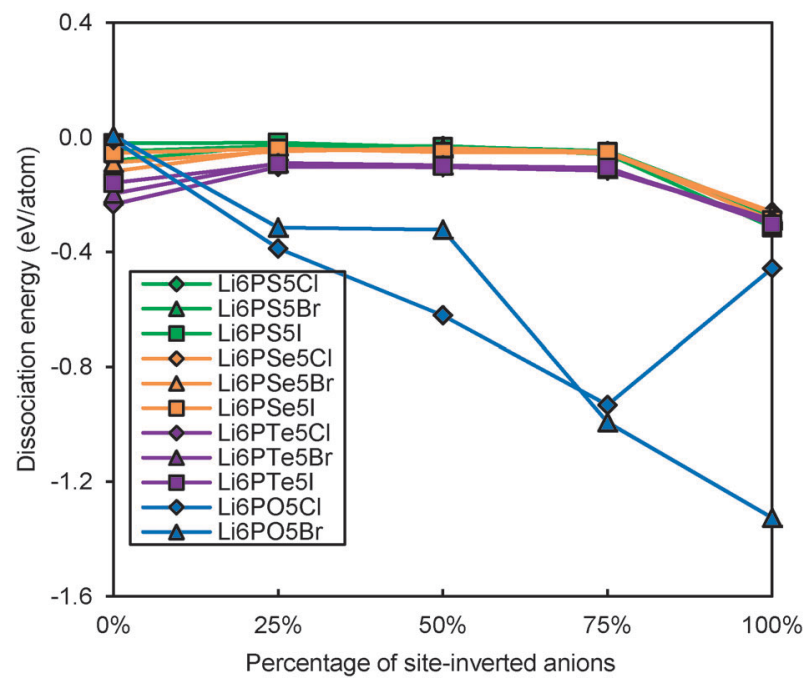

Fig. 15 Effect of anion site-inversion on the dissociation energy of $\mathrm{Y}$-argyrodites where $\mathrm{Y}=\mathrm{O}, \mathrm{S}, \mathrm{Se}, \mathrm{Te}$ as a function of the halide content. 


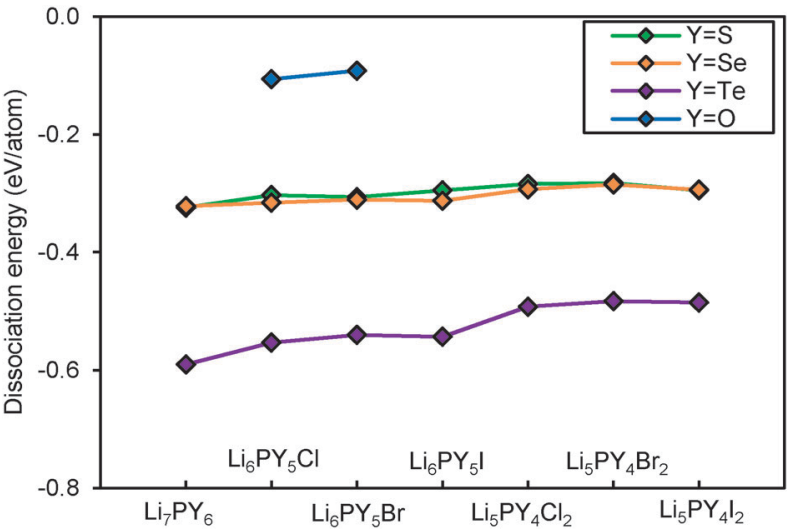

Fig. 16 Hydrolysis stability of $\mathrm{Y}$-argyrodites.

compounds the stability differences between the compounds with the two structure types are much smaller.

Fig. 15 plots the dissociation energy versus degree of siteinversion in Y-argyrodites. Selenium and tellurium argyrodites share the same trend as sulphur argyrodites that fully ordered configurations are less stable. In contrast the oxygen argyrodites can only exist in the fully ordered configuration. This is consistent with the experimental structure determination of oxygen argyrodites. ${ }^{45}$

Hydrolysis stability. Critical reactions for determining the hydrolysis stabilities of argyrodites containing different $\mathrm{Y}^{2-}$ anions are eqn (6), (20), and (21):

$$
\begin{gathered}
\mathrm{Li}_{6} \mathrm{PO}_{5} \mathrm{X}+\mathrm{H}_{2} \mathrm{O} \leftrightarrow \mathrm{LiX}+\mathrm{Li}_{3} \mathrm{PO}_{4}+2 \mathrm{LiOH} \\
\mathrm{Li}_{6} \mathrm{PSe}_{5} \mathrm{X}+(8-2 x) \mathrm{H}_{2} \mathrm{O} \leftrightarrow x \mathrm{LiX}+\mathrm{Li}_{3} \mathrm{PO}_{4}+(6-x) \mathrm{Se} \\
+(6-x) \mathrm{H}_{2}+(4-2 x) \mathrm{LiOH} \\
\mathrm{Li}_{6} \mathrm{PTe}_{5} \mathrm{X}+(8-2 x) \mathrm{H}_{2} \mathrm{O} \leftrightarrow x \mathrm{LiX}+\mathrm{Li}_{3} \mathrm{PO}_{4}+(6-x) \mathrm{Te} \\
+(6-x) \mathrm{H}_{2}+(4-2 x) \mathrm{LiOH}
\end{gathered}
$$

Fig. 16 shows the resulting hydrolysis dissociation energies of argyrodites. Oxygen argyrodites have the highest calculated hydrolysis stability, in line with the general tendency that oxides are more stable to moisture than sulphides, selenides and tellurides. Similar to the findings for structural stability, selenium argyrodites and sulphur argyrodites have nearly the same level of hydrolysis stability. The hydrolysis products are different, with selenium argyrodites releasing $\mathrm{H}_{2}$ while sulphur argyrodites releasing $\mathrm{H}_{2} \mathrm{~S}$. Though $\mathrm{H}_{2} \mathrm{Se}$ and $\mathrm{H}_{2} \mathrm{Te}$ exist in gaseous form, they are not stable and would decompose into $\mathrm{H}_{2}$ and $\mathrm{Se} / \mathrm{Te}$.

Activation energy for $\mathrm{Li}^{+}$migration. Fig. 17 shows the activation energy for the migration ${\mathrm{of} \mathrm{Li}^{+}}^{+}$in the compounds containing different $\mathrm{Y}^{2-}$ anions. Consistent with experimental observation, activation energies of $\mathrm{Li}_{6} \mathrm{PO}_{5} \mathrm{Cl}$ and $\mathrm{Li}_{6} \mathrm{PO}_{5} \mathrm{Br}$ are higher than those of $\mathrm{Li}_{6} \mathrm{PS}_{5} \mathrm{Cl}$ and $\mathrm{Li}_{6} \mathrm{PS}_{5} \mathrm{Br}$. The comparison to selenide- and telluride-based compounds is based on an estimated scaling factor of 0.5 , as only two experimental activation energies $0.49 \mathrm{eV}$ of $\mathrm{Li}_{7} \mathrm{PSe}_{6}{ }^{52}$ and $0.20 \mathrm{eV}$ of $\mathrm{Li}_{6} \mathrm{PSe}_{5} \mathrm{Br}^{43}$ are available for comparison. Unlike for the case of the sulphur

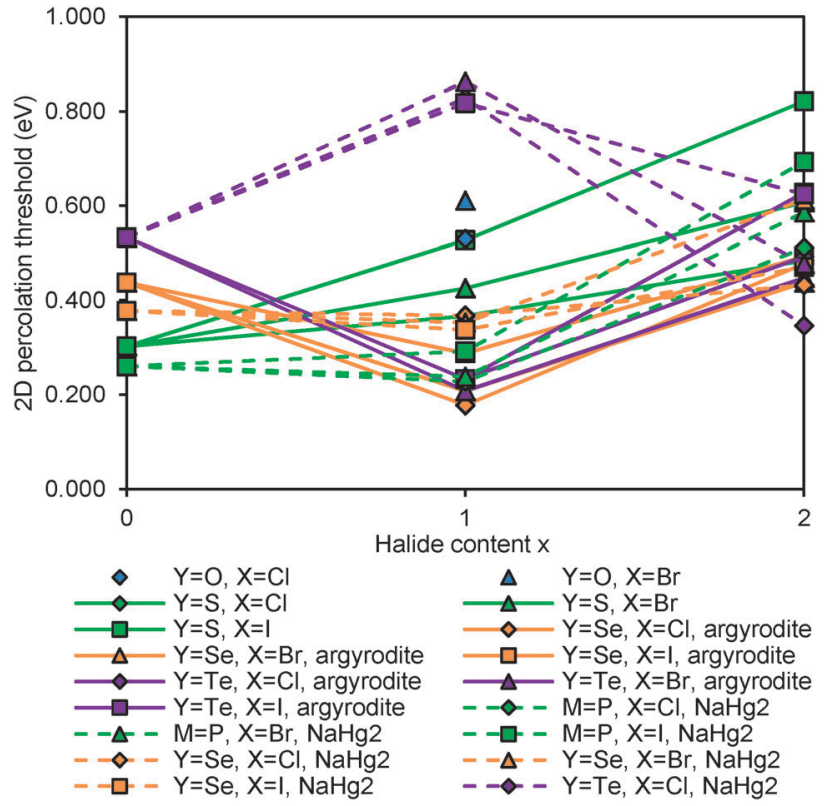

Fig. 17 Activation energies for $\mathrm{Li}^{+}$migration in compounds containing different $\mathrm{Y}^{2-}$ anions.

argyrodites, among the argyrodites with $\mathrm{Y}=\mathrm{Se}$, Te the $\mathrm{Li}_{6} \mathrm{PY}_{5} \mathrm{X}$ compositions with intermediate halide content have lower activation energies than the halide-free $\mathrm{Li}_{7} \mathrm{PY}_{6}$ and halide-rich $\mathrm{Li}_{5} \mathrm{PY}_{4} \mathrm{X}_{2}$ argyrodites. In fact the activation energies predicted for $\mathrm{Li}_{6} \mathrm{PSe}_{5} \mathrm{X}$ with $\mathrm{X}=\mathrm{Cl}, \mathrm{Br}$ are the lowest of all the studied argyrodite compositions. The $\mathrm{Li}_{6} \mathrm{PY}_{5} \mathrm{X}$ argyrodites with $\mathrm{Y}=\mathrm{Se}$, Te also have somewhat lower activation energies than the $\mathrm{NaHg}_{2}$-related phases of the same composition.

Bandgaps and selection guidelines. The DFT-calculated bandgaps of argyrodites $\mathrm{Li}_{6} \mathrm{PY}_{5} \mathrm{Br}$ decrease in the order $\mathrm{O}>$ $\mathrm{S}>\mathrm{Se}>\mathrm{Te}$ as tabulated in Table 1. In general bandgaps are predicted to decrease as the period of anion $\mathrm{Y}$ increases since higher electron density should promote electronic conduction. The high bandgap of the oxide argyrodite clearly qualifies it as an insulator. From the calculations $\mathrm{Li}_{6} \mathrm{PS}_{5} \mathrm{Br}$ should be a semiconductor with a bandgap of $2.12 \mathrm{eV}$. Still it has to be kept in mind that DFT calculations using GGA functionals tend to underestimate the band gap and practically an electrochemical window $>4 \mathrm{eV}$ has been concluded from cyclovoltammetry. ${ }^{20}$ Similarly, prediction of $\mathrm{Li}_{6} \mathrm{PTe}_{5} \mathrm{Br}$ to be a metal in practice might suggest that it is a narrow-band semiconductor, but definitely not suitable as a solid electrolyte. For $\mathrm{Li}_{6} \mathrm{PSe}_{5} \mathrm{Br}$ the intermediate bandgap may indicate that this may be a mixed conductor with (in view of the low activation energy for $\mathrm{Li}^{+}$migration) mainly ionic conductivity but substantial contributions of electronic

Table 1 Bandgaps of argyrodites $\mathrm{Li}_{6} \mathrm{PY}_{5} \mathrm{Br}$ containing different $\mathrm{Y}^{2-}$ anions

\begin{tabular}{ll} 
Argyrodite cubic phase & Calculated bandgap (eV) \\
\hline $\mathrm{Li}_{6} \mathrm{PO}_{5} \mathrm{Br}$ & 5.67 \\
$\mathrm{Li}_{6} \mathrm{PS}_{5} \mathrm{Br}$ & 2.12 \\
$\mathrm{Li}_{6} \mathrm{PSe}_{5} \mathrm{Br}$ & 1.00 \\
$\mathrm{Li}_{6} \mathrm{PTe}_{5} \mathrm{Br}$ & 0.00
\end{tabular}


conductivity preventing use of pure selenides as a solid electrolyte, but potentially of interest in compounds with e.g. $\mathrm{S}^{2-} / \mathrm{Se}^{2-}$ anion disorder.

Based on these calculations the stability and electrochemical window of argyrodites should increase in the order of Te $\ll$ Se $<$ $\mathrm{S}<\mathrm{O}$. While selenium argyrodites might be accessible, their limited stability will probably remain an issue for practical applications. Among the four classes of argyrodites, sulphur argyrodites still strike the best balance between stability and conductivity.

\section{Concluding remarks}

The search for solid electrolyte materials is often a compromise between chemical stability and ionic conductivity of a compound. Using argyrodite systems as an example, a systematic evaluation of structural stability, hydrolysis stability, ionic conductivity and electronic conductivity is achieved combining various computational techniques. The results show that there is significant room for synthesizing argyrodite compounds with improved stability and conductivity as solid electrolyte materials for ion-conducting rechargeable batteries.

\section{Acknowledgements}

This research is supported by the National Research Foundation, Prime Minister's office, Singapore under its Competitive Research Programme (CRP Awards No. NRF-CRP 10-2012-6 and NRF-CRP 8-2011-04).

\section{References}

1 M. Tatsumisago, M. Nagao and A. Hayashi, J. Australas. Ceram. Soc., 2013, 1, 17-25.

2 P. Knauth, Solid State Ionics, 2009, 180, 911-916.

3 H. Yamane, M. Shibata, Y. Shimane, T. Junke, Y. Seino, S. Adams, K. Minami, A. Hayashi and M. Tatsumisago, Solid State Ionics, 2007, 178, 1163-1167.

4 Y. Seino, T. Ota, K. Takada, A. Hayashi and M. Tatsumisago, Energy Environ. Sci., 2014, 7, 627-631.

5 N. Kamaya, K. Homma, Y. Yamakawa, M. Hirayama, R. Kanno, M. Yonemura, T. Kamiyama, Y. Kato, S. Hama, K. Kawamoto and A. Matsui, Nat. Mater., 2011, 10, 682-686.

6 S. Adams and R. P. Rao, J. Mater. Chem., 2012, 22, 7687-7691.

7 R. Kanno, T. Hata, Y. Kawamoto and M. Irie, Solid State Ionics, 2000, 130, 97-104.

8 E. Rangasamy, Z. Liu, M. Gobet, K. Pilar, G. Sahu, W. Zhou, H. Wu, S. Greenbaum and C. Liang, J. Am. Chem. Soc., 2015, 137, 1384-1387.

9 S. Adams and J. Swenson, Phys. Chem. Chem. Phys., 2002, 4, 3179-3184.

10 H.-J. Deiseroth, S.-T. Kong, H. Eckert, J. Vannahme, C. Reiner, T. Zaiß and M. Schlosser, Angew. Chem., Int. Ed., 2008, 47, 755-758.

11 C. Winkler, Ber. Bunsen-Ges., 1886, 19, 210-211.
12 D. Frank, B. Gerke, M. Eul, R. Pöttgen and A. Pfitzner, Chem. Mater., 2013, 25, 2339-2345.

13 C. Palache, H. Berman and C. Frondel, Dana's system of mineralogy, John Wiley \& Son's, New York, 7th edn, 1944, vol. 1, pp. 356-358.

14 (a) W. F. Kuhs, R. Nitsche and K. Scheunemann, Mater. Res. Bull., 1979, 14, 241-248; (b) W. F. Kuhs and G. Heger, in Fast ion transport in solids: electrodes, and electrolytes, ed. P. Vashishta, J. N. Mundy and G. K. Shenoyeds, Proceedings of the International Conference on Fast Ion Transport in Solids, Electrodes, and Electrolytes, Lake Geneva, Wisconsin, USA, May 21-25, Elsevier, Amsterdam, 1979, pp. 233-236.

15 (a) M. Evain, E. Gaudin, F. Boucher, V. Petricek and F. Taulelle, Acta Crystallogr., Sect. B: Struct. Sci., Cryst. Eng. Mater., 1998, 54, 376-383; (b) E. Gaudin, F. Boucher, V. Petricek, F. Taulelle and M. Evain, Acta Crystallogr., Sect. B: Struct. Sci., Cryst. Eng. Mater., 2000, 56, 402-408; (c) E. Gaudin, V. Petricek, F. Boucher, F. Taulelle and M. Evain, Acta Crystallogr., Sect. B: Struct. Sci., Cryst. Eng. Mater., 2000, 56, 972-979.

16 (a) H. Wada, J. Alloys Compd., 1992, 178, 315-323; (b) H. Wada, A. Sato, M. Onoda, S. Adams, M. Tansho and M. Ishii, Solid State Ionics, 2002, 154-155, 723-727.

17 A. S. Kinduris, R. A. Bendoryus and D. B. Senulene, Sov. Phys. Semicond., 1976, 10, 916-917.

18 (a) R. P. Rao and S. Adams, Phys. Status Solidi A, 2011, 208, 1804-1807; (b) S. Adams and R. Prasada Rao, Understanding Ionic Conduction and Energy Storage Materials with BondValence-Based Methods, in Bond Valences, Structure and Bonding, ed. I. D. Brown and K. R. Poeppelmeier, Springer, Berlin, Heidelberg, 2014, vol. 158, pp. 129-159.

19 R. P. Rao, N. Sharma, V. K. Peterson and S. Adams, J. Solid State Electrochem., 2012, 16, 1807-1813.

20 M. Chen, R. P. Rao and S. Adams, Solid State Ionics, 2014, 262, 183-187.

21 R. P. Rao, N. Sharma, V. K. Peterson and S. Adams, Solid State Ionics, 2013, 230, 72-76.

22 M. Ishii, M. Onoda and K. Shibata, Solid State Ionics, 1999, 121, 11-18.

23 A. Haznar, A. Pietraszko and I. P. Studenyak, Solid State Ionics, 1999, 119, 31-36.

24 (a) M. Wagener, H.-J. Deiseroth and C. Reiner, Z. Kristallogr., 2006, 221, 533-538; (b) M. Wagener, PhD thesis, University of Siegen, 2005.

25 M. V. Moroz, P. Y. Demchenko, L. G. Akselrud, O. G. Mykolaychuk and R. E. Gladyshevskii, Chem. Met. Alloys, 2010, 3, 161-168.

26 O. G. Mykolaychuk, N. V. Moroz, P. Yu. Demchenko, L. G. Akselrud and R. E. Gladyshevskii, Inorg. Mater., 2010, 46, 590-597.

27 N. A. W. Holzwarth, N. D. Lepley and Y. A. Du, J. Power Sources, 2011, 196, 6870-6876.

28 S. Adams, Solid State Ionics, 2000, 136, 1351-1361.

29 (a) S. Adams and R. P. Rao, Phys. Status Solidi A, 2011, 208, 1746-1753; (b) S. Adams and R. P. Rao, in Bond Valences, ed. I. D. Brown and K. R. Poeppelmeier, Springer-Verlag, Berlin Heidelberg, 2014, ch. 5, pp. 129-159. 
30 S. Adams and R. P. Rao, Solid State Ionics, 2011, 184, 57-61.

31 G. Kresse and J. Furthmüller, Phys. Rev. B: Condens. Matter Mater. Phys., 1996, 54, 11169-11186.

32 J. P. Perdew, K. Burke and M. Ernzerhof, Phys. Rev. Lett., 1996, 77, 3865-3868.

33 P. E. Blöchl, Phys. Rev. B: Condens. Matter Mater. Phys., 1994, 50, 17953.

34 G. Kresse and J. Joubert, Phys. Rev. B: Condens. Matter Mater. Phys., 1999, 59, 1758.

35 L. Wang, T. Maxisch and G. Ceder, Phys. Rev. B: Condens. Matter Mater. Phys., 2006, 73, 195107.

36 GNU Linear Programming Kit, version 4.55, http://www.gnu. org/software/glpk/glpk.html.

37 S. Adams, Practical Considerations in Determining Bond Valence Parameters, in Bond Valences, Structure and Bonding, ed. I. D. Brown and K. R. Poeppelmeier, Springer, Berlin, Heidelberg, 2014, vol. 158, pp. 91-128.

38 L. L. Wong, H. M. Chen and S. Adams, Phys. Chem. Chem. Phys., 2015, 17, 9186-9193.

39 M. J. S. Dewar, E. F. Healy and J. J. P. Stewart, J. Chem. Soc., Faraday Trans. 2, 1984, 280, 227-233.

40 S.-T. Kong, H.-J. Deiseroth, C. Reiner, Ö. Gün, E. Neumann, C. Ritter and D. Zahn, Chem. - Eur. J., 2010, 16, 2198-2206.
41 H.-J. Deiseroth, J. Maier, K. Weichert, V. Nickel, S.-T. Kong and C. Reiner, Z. Anorg. Allg. Chem., 2011, 637, 1287-1294.

42 S. Boulineau, M. Courty, J.-M. Tarascon and V. Viallet, Solid State Ionics, 2012, 221, 1-5.

43 V. Epp, Ö. Gün, H.-J. Deiseroth and M. Wilkening, J. Phys. Chem. Lett., 2013, 4, 2118-2123.

44 O. Pecher, S.-T. Kong, T. Goebel, V. Nickel, K. Weichert, C. Reiner, H.-J. Deiseroth, J. Maier, F. Haarmann and D. Zahn, Chem. - Eur. J., 2010, 16, 8347-8354.

45 S.-T. Kong, H.-J. Deiseroth, J. Maier, V. Nickel, K. Weichert and C. Reiner, Z. Anorg. Allg. Chem., 2010, 636, 1920-1924.

46 S.-T. Kong, O. Gün, B. Koch, H.-J. Deiseroth, H. Eckert and C. Reiner, Chem. - Eur. J., 2010, 16, 5138-5147.

47 W. H. Paar, A. C. Roberts, P. Berlepsch, T. Armbruster, D. Topa and G. Zagler, Can. Mineral., 2004, 42, 1757-1769.

48 A. Ggor, A. Pietraszko and D. Kaynts, J. Solid State Chem., 2005, 178, 3366-3375.

49 T. Nilges and A. Pfitzner, Z. Kristallogr., 2005, 220, 281-294.

50 Q. Shi, Master thesis, Shandong University, 2012.

51 R. H. P. Francisco, J. Solid State Chem., 1993, 107, 452-459.

52 V. Epp, Ö. Gün, H.-J. Deiseroth and M. Wilkening, Phys. Chem. Chem. Phys., 2013, 15, 7123-7132. 